\title{
APPLICATION OF GLAZING COATING FOR WINDOW RETROFIT IN THE CANADIAN CONTEXT
}

by

Md Mostafizur Rahman

Bachelor of Architecture (B.Arch.)

Bangladesh University of Engineering and Technology (BUET), Dhaka. 2003

Master of Science in Urban Management and Development (UMD)

IHS, Erasmus University Rotterdam (EUR), The Netherlands, 2010

An MRP presented to Ryerson University

in partial fulfillment of the requirements for the degree of

Master of Building Science

in the Program of Building Science

Toronto, Ontario, Canada, 2019

(C) Md Mostafizur Rahman, 2019 


\section{AUTHOR'S DECLARATION FOR ELECTRONIC SUBMISSION OF AN MRP}

I hereby declare that I am the sole author of this MRP. This is a true copy of the MRP, including any required final revisions.

I authorize Ryerson University to lend this MRP to other institutions or individuals for the purpose of scholarly research

I further authorize Ryerson University to reproduce this MRP by photocopying or by other means, in total or in part, at the request of other institutions or individuals for the purpose of scholarly research.

I understand that my MRP may be made electronically available to the public. 


\title{
Application of Glazing Coating for Window Retrofit in the Canadian Context
}

Md Rahman

Master of Building Science

Building Science, Ryerson University, 2019

\begin{abstract}
Windows offer lots of opportunities to the building occupants but also are responsible for significant energy load for the buildings, especially in the older buildings, due to heat loss in winter and heat gain in summer. One way of achieving better performance and save energy is to use the high-performance window. Which option between window retrofit and window replacement is right in Canada? A new glazing coating that can be used for windows retrofit is investigated. The purpose of the study is to research the improved spectral values obtained with this coating, and it's actual energy performance when applied to the existing windows of the buildings in the Canadian context. To reach the goal laboratory test data of the SNG SC coated sample glazing were collected first, then used for energy performance modelling, simulation and analysis.
\end{abstract}

Keywords: Windows retrofit, SNG SC coating, Software's, Energy analysis. 


\section{Acknowledgements}

I want to thank my supervisor Dr. Umberto Berardi whose help, suggestions, constructive criticism and encouragement helped me in all the time of the research for the writing of this MRP. I have enjoyed every meeting with you.

I am grateful to the graduate program of Building Science and Ryerson University for offering me the opportunity to study this master's degree.

I also want to thank Dr. Russell Richman for providing the theoretical knowledge of building envelopes and introduction to new enhanced envelope analysis tool; he inspired me to conduct this research.

I also would like to thank Dr. Miljana Horvat and Prof. Hitesh Doshi for their constructive suggestions and help during the course.

The greatest thanks and pleasure to my wife, Suraya Akhtar and children, Eusha A. Nur \& Eylhan A. Nur, my parents and all my family members for their support, prayers, sacrifice and love so that I finally can reach this step of my life.

I don't forget to thank all the teaching and administration staff of Building Science-Ryerson University, who have supported and given big help during my study here.

To all my colleagues from graduate program building science participants, I express my big thanks for your help, support and all the things you have shown to me. It has been an unforgettable moment to have known you all.

Md Mostafizur Rahman,

December 2018 


\section{Table of Contents}

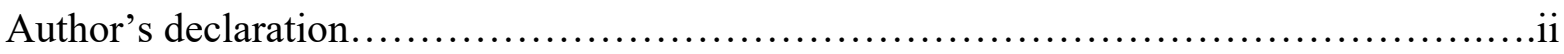

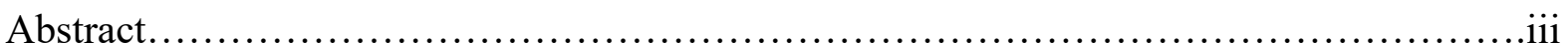

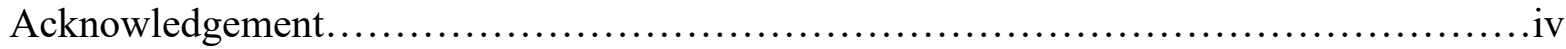

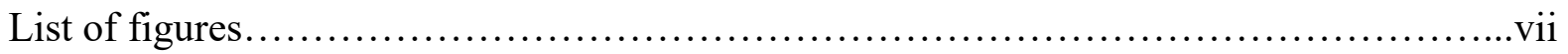

List of Tables..................................................................

\section{Introduction}

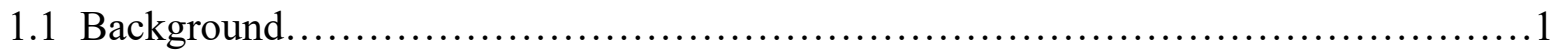

1.2 Objective \& Research Question...................................................

\section{Literature Review}

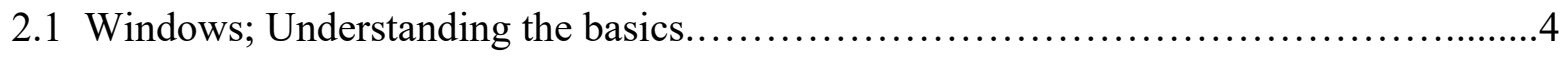

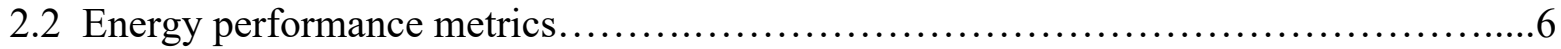

2.3 Performance ratings; criteria and standards......................................

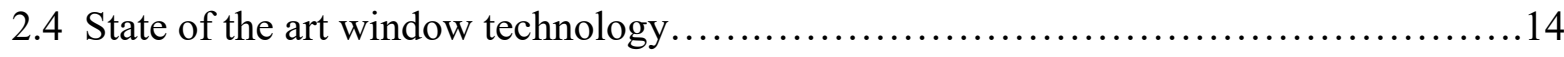

2.5 Energy efficiency in window; facts and myths.............................. 15

2.6 Windows energy retrofit guidelines........................................... 16

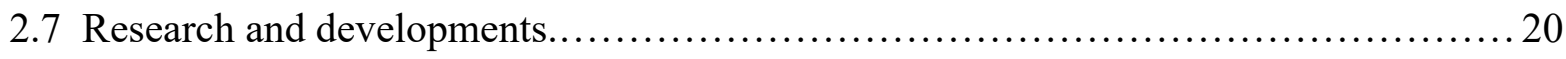

$2.8 \mathrm{COMFEN}$; an early design tools for retrofit analysis......................... 21

\section{SketchNanoGard (SNG-SC) Coating}

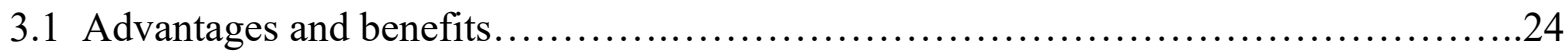

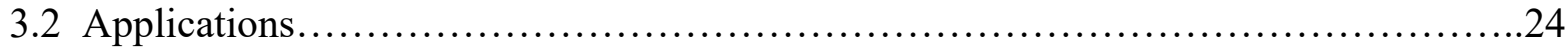

\section{Research Method}

4.1 Energy performance modelling, simulation and analysis........................26

\section{Results}

5.1 Annual energy savings analysis for Toronto.................................. 32

5.2 Window wall ratio (WWR) and energy demand...................................

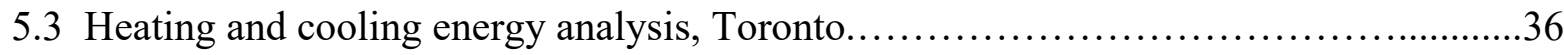


5.4 Annual energy savings analysis for other cities.................................. 37

5.5 Heating and cooling energy analysis among other cities........................... 39

5.6 The payback time calculation for all cities..................................... 41

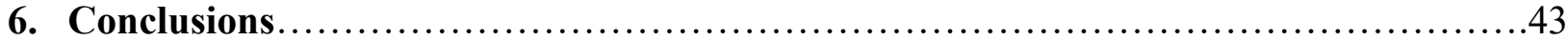

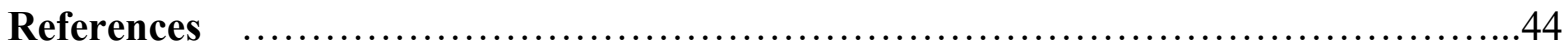




\section{List of Figures}

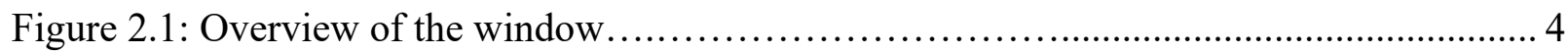

Figure 2.2: $\mathrm{U}$ value and heat loss through the edge and center of glass and frame.............. 7

Figure 2.3: Mechanism of heat transfer in windows....................................... 8

Figure 2.4: Visible spectrum and wavelengths corresponding to different colours............ 9

Figure 2.5: Ideal spectral transmittance for glazing ........................................ 10

Figure 2.6: ENERGY STAR Zone 1-3 (HDD's) ............................................. 12

Figure 2.7: Example of Energy Star Labels .............................................. 13

Figure 2.8: Typical components of IGU and Low conductance gas fills...................... 14

Figure 2.9: Typical Low-E coating position on the glass surface ....................................20

Figure 2.10: Overview of the COMFEN program interface ............................... 21

Figure 3.1: SNG-SC coating application techniques …................................ 25

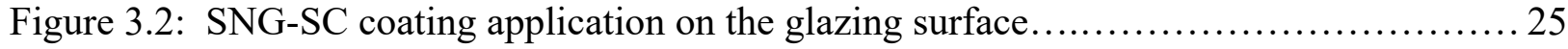

Figure 4.1: The overview of the research method................................................ 26

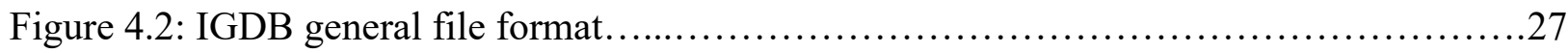

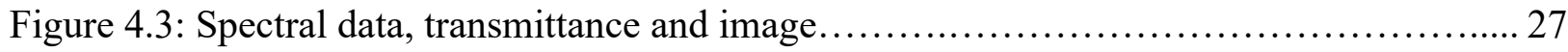

Figure 4.4: Proposed room and windows size with different orientations.......................29

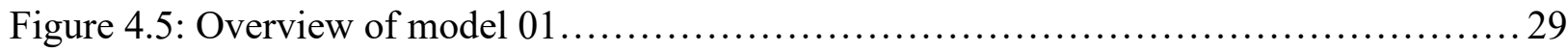

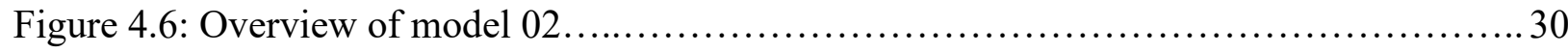

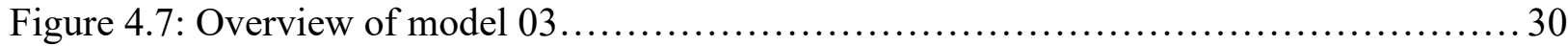

Figure 5.1: Energy use intensity for the fixed window in Toronto................................ 32

Figure 5.2: Energy use intensity for the operable window in Toronto.......................... 33

Figure 5.3: Energy use intensity for the curtain wall in Toronto............................... 34

Figure 5.4: Impact of window wall ratio on energy performance in Toronto......................35

Figure 5.5: Heating and cooling energy savings pattern in Toronto........................... 36

Figure 5.6: Energy consumption for the fixed window among cities........................... 37

Figure 5.7: Energy consumption (operable window) compared among cities....................38

Figure 5.8: Heating energy consumption among towns..................................... 39

Figure 5.9: Cooling energy consumption pattern among cities...............................41

Figure 5.10: Payback time calculation among cities.....................................42 


\section{List of Tables}

Table 2.1: Windows qualifying Criteria for ENERGY STAR $\ldots \ldots \ldots \ldots \ldots \ldots \ldots \ldots \ldots \ldots \ldots \ldots$

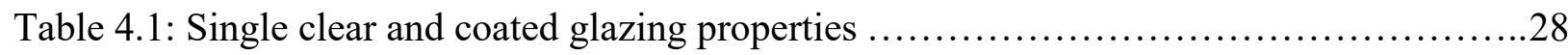

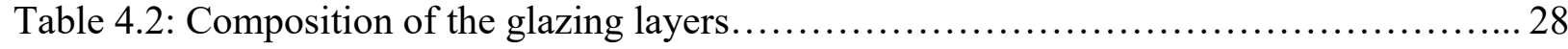

Table 4.3: Glazing systems and properties....................................... 28

Table 5.1: Energy savings intensity for the fixed window in Toronto..................... 32

Table 5.2: Energy savings intensity for the operable window in Toronto.................... 34

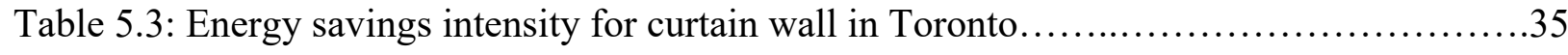

Table 5.4: Heating and Cooling energy savings in Toronto............................... 37

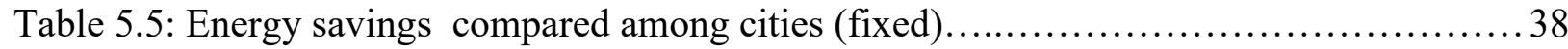

Table 5.6: Energy savings compared among cities (operable)........................... 39

Table 5.7: SNG-SC coating heating energy savings among cities...................... 40

Table 5.8: SNG-SC coating cooling energy savings among cities....................... 40 


\section{INTRODUCTION}

\subsection{Background}

It has often said that windows are the eyes of the home, allowing the occupants the opportunity to observe what is happening outside (NRCan, 2003). Besides, they provide natural light, ventilation and have an impact on the health, productivity and well-being of the occupants. Windows also present a significant energy load to buildings, especially in older buildings with poorly insulating windows due to heat loss in winter and heat gain in summer and modern high-rise buildings with large window wall ratio (WWR).

The Department of Energy (DOE) estimated that 30\% of the energy used to heat and cool all buildings in the United States, lost through inefficient windows, which resulted in a cost of $\$ 42$ billion per year (Peng, Goudey, Thanachareonki and Lee, 2017). Various research studies have shown that in a typical Canadian house with conventional double-pane clear-glass windows, solar gain typically provides from $10 \%$ to $27 \%$ of the total heating energy and the heat loss during in winter may account for more than $27 \%$ of the total heat loss (Armstrong, Elmahdy, Swinton and Parekh 2008).

One way of achieving better performance is using high-performance windows or developing advanced windows technologies which provide better thermal performance than clear window glazing. There are two options to reduce the amount of energy lost through windows and enhance the comfort of the home; update existing windows or replace them to improve efficiency (Schroeder, 2018). When specifying upgrade or replacement of windows, both the quality of light they introduce into the building as well as their thermal performance must be considered. In recent years, Canadians have spent more on renovations than on new construction and windows represent one of the most significant single investments in a typical repair (NRCan, 2003).

Canada is a heating dominated climate, so installing high solar gain windows would be an obvious choice to allow solar energy to enter the buildings in winter, whereas in summer windows need to 
block the heat. We need strategies that reduce the building's heating and cooling load, to maintain occupant comfort and less money on energy bill (NREL, 2018). Fortunately, technical breakthroughs have improved windows technology, and there is considerable potential for reducing both the heating and cooling energy use in existing buildings associated with windows by using a wide range of technologies and strategies (LBNL, 2014).

It has been estimated that replacing the entire existing commercial building windows systems with typical low-E double pane windows (U-factor $2.27 \mathrm{~W} / \mathrm{m}^{2} \cdot \mathrm{K}$ and SHGC=0.29) in the United States could save 0.32 quads (or 62\%) of the annual commercial building cooling energy, which is equivalent to the annual energy consumed by roughly 1.8 million U.S. households (Peng et al., 2017). Choosing ENERGY STAR certified models in Canada can save an average of $8 \%$ on energy bills and that approved to the ENERGY STAR most efficient specification (U-value of 1.14 $\mathrm{W} / \mathrm{m}^{2} \cdot \mathrm{K}$ or lower) are even more efficient up to $40 \%$ compared to a standard double-pane window (NRCan, 2018).

Replacing the entire existing building window stock with typical low-E double glazing windows can save a tremendous amount of energy but is often complicated depending on the design of existing construction and can be very expensive too (Apte and Arasteh 2006). Therefore, it is also essential to consider retrofit options that provide equivalent energy performance gains while making use of the existing installed glass and framing (LBNL, 2014). It is possible to achieve a significant energy saving with windows retrofits such as applied films or coatings available in the Canadian market with a durable, low emittance surface that will improve the insulation performance. Coating can minimize heat radiated through the window, control solar heat gain for occupant's comfort during the early and later parts of the day and can maximize visible light transmittance for daylighting. As numerous factors affect windows annual energy performance (Armstrong et al., 2008), making it challenging to answer the question: Which option will provide the best energy and cost savings performance in the Canadian context?

So, Sketch NanoGard SC (SNG-SC) thermal liquid glazing coating that can be used for the windows retrofit has been selected for this study to conduct extensive research. 


\subsection{Objective and Research Question}

The purpose of the study is to research the improved spectral values obtained with this coating and it's actual energy performance when applied to the existing windows of the buildings in the Canadian context. The research will try to explore a better explanation of the following question.

- What is the energy saving potential of the SNG-SC coating compared to the double clear air and double low-E argon glazing unit for the proposed options? 


\section{LITERATURE REVIEW}

\subsection{Window: Understanding the Basics}

Window is an assembled unit consisting of a frame/sash component holding one or more pieces of glazing functioning to admit light and air into an enclosure and designed for vertical installation in an external wall of a residential building (NRCan, 2018).

There are two basic types of window; fixed and operable. Fixed windows are more efficient and safer because of their airtightness characteristics, but it is often desirable to be able to open a window for ventilation or an escape route for an emergency. There are many forms of operable unit: awning, casement, hopper, horizontal and vertical slider (either single or double hung) and turn-and-tilt (NRCan, 2003).

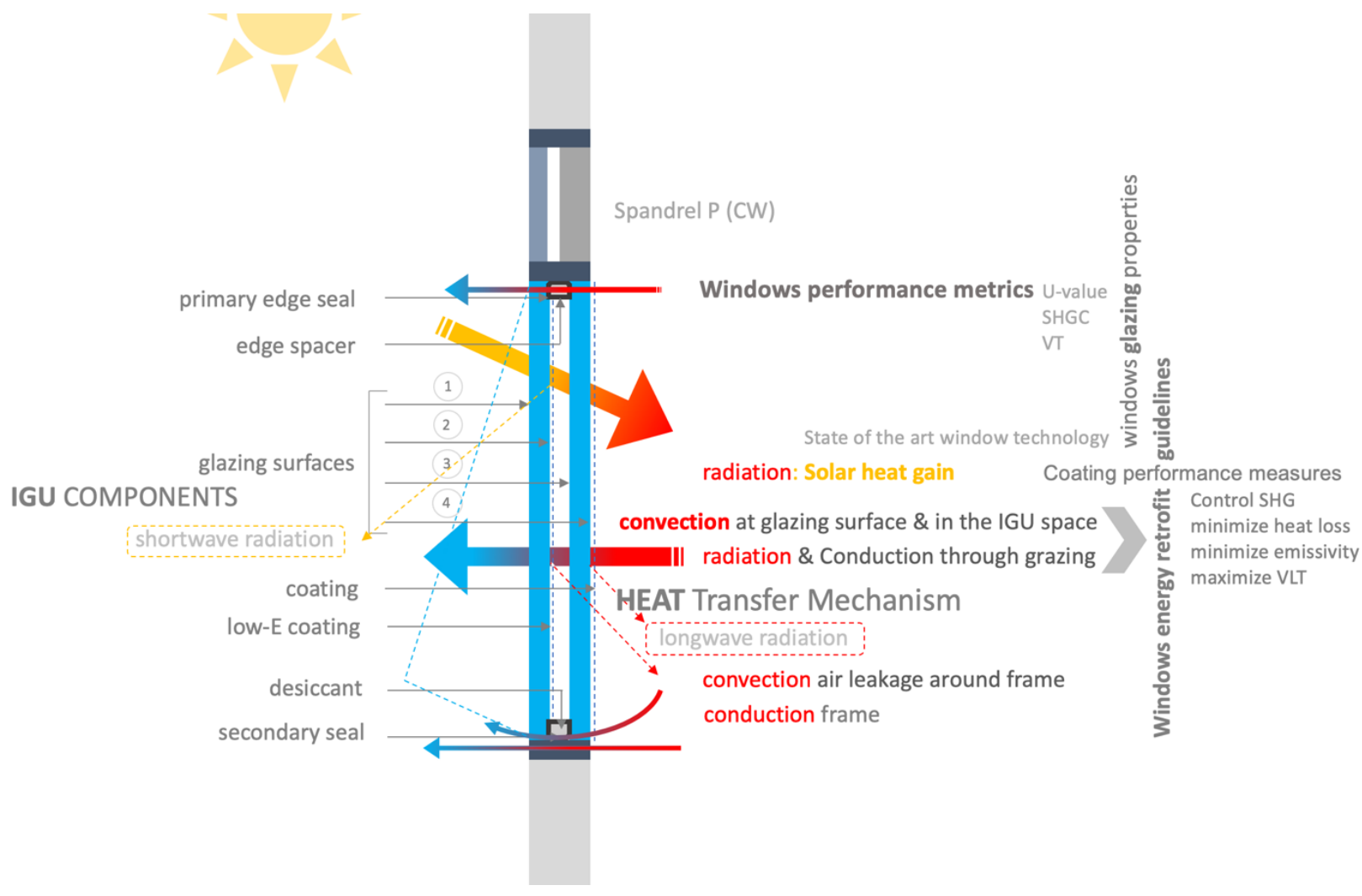

Figure: 2.1 Overview of the window. 
The window has only vision glazing, whereas curtain wall and window walls have both vision glazing and opaque (spandrel) panels mounted in a metal frame system.

Glazing is the generic term for transparent or translucent materials in a window system, made of glass or plastic (acrylic or polycarbonate). Common types of glazing that are used in the architectural application include clear and tinted float glass, tempered glass, laminated glass as well as a variety of coated glass, all of which can be single, double or even triple glazed units (GG, 2018). For the harsh Canadian climates, it is recommended that all windows should be at least double-glazed (NRCan, 2011).

Frosted and patterned glass does not significantly reduce the amount of sun's heat and visible light coming into the home however tinted glass do both and may have an impact on either heating or cooling costs.

A window consists of a glazed unit that fits into the sash, and the structure holds the sash. The frame and sash can be significant sources of heat loss due to conduction through the window frame.

\subsubsection{Insulating glazing unit (IGU)}

The IGU consists of at least two panes of glass. IGUs are typically filled with an inert gas such as argon or krypton to reduce heat transfer through the glazing (NRCan, 2018). A spacer bar is placed between the glazing to maintain a uniform separation between the panes. The spacer bar has desiccant in it to absorb the moisture to prevent fogging between the panes. Some IGUs made from Low-E coatings can dramatically reduce the amount of the sun's heat coming into the home during summer and heat escaping from inside during winter depends on the types of surface coating. LowE coated glass has a microscopically thin transparent metal coating that reflects long-wave infrared energy during winter and blocks shortwave gain in the summer.

There are two different types of Low-E coatings; passive Low-E coatings and solar control LowE coatings (Vitro, 2018). Passive low-E coatings designed to maximize solar heat gain into a home and solar control Low-E coatings intended to limit the amount of solar heat that passes through the window into a home. Both types of Low-E glass, passive and solar control, are produced by two primary production methods; pyrolytic, or "hard coat," and Magnetron Sputter Vacuum Deposition 
(MSVD), or "soft coat" (Vitro, 2018). Low-emissivity coatings usually applied to glass at the manufacturing stage, and this option is limited to older homes unless the owner is interested in replacing the whole or part of the window.

\subsubsection{Emerging glazing technologies}

The following technological advances promise significant gains in windows efficiency (NRCan, 2018).

- Vacuum IG units: Which have no air or inert gas inside, so the conduction and convection of heat between the panes is almost nil. Vacuum IGU transfer significantly less heat than standard gas-filled units (NRCan, 2018).

- Aerogel glazing: It uses a highly insulating, low-density silica-based (aerogel) solid between the glass panes that dramatically reducing heat transfer.

- Electrochromic glazing: Sometimes it is called smart glazing (switchable) can reduce solar gain and light passing through the glass only when it's necessary. It offers a variety of control options; users can operate it according to needs.

Currently, only electrochromic glazing is available in the market and used mainly in the commercial building.

\subsection{Windows energy performance metrics}

Windows energy performance depends on how they allow a home to gain energy from the sun, and how they affect energy loss when the sun is not shining. It is not surprising in Canada when it comes to window energy performance; focus is keeping the heat in and capturing free heat from the sun. Which windows will be more useful depends on three fundamental performance properties; U factor, Solar heat gain coefficient (SHGC) and air leakage and how do they interact? In addition to these, there is an energy performance property used in Canada, that called the energy rating or ER (RDH, 2017). 


\subsubsection{U-Value (The rate of heat loss)}

The U-Value is a measure of the overall rate at which heat escapes through a window when there is a temperature difference due to the combined effect of conduction, convection and radiation. Heat travels at different rates through the frame, the edge of the glass and the center of the glazing. The U-value represents the overall rate of heat transfer through all these components (Hanam, 2012) and express in either metric units $\left(\mathrm{W} / \mathrm{m}^{2} . \mathrm{K}\right)$ or inch-pound units $\left(\mathrm{Btu} / \mathrm{h} . \mathrm{ft}^{2}{ }^{{ }^{0}}{ }^{\mathrm{F}}\right)$. Known the Uvalue, the R-value can be obtained by the expression; 1/U-value.

The U-factor is affected by the total number of glazing layers, their thickness, type of gas between layers, the characteristic of coatings, and the angle of orientation. Lower U-values are always desirable as they represent less heat transfer (primarily winter heat loss) and, therefore, less energy needed for heating and cooling (Okanaganway, 2018).
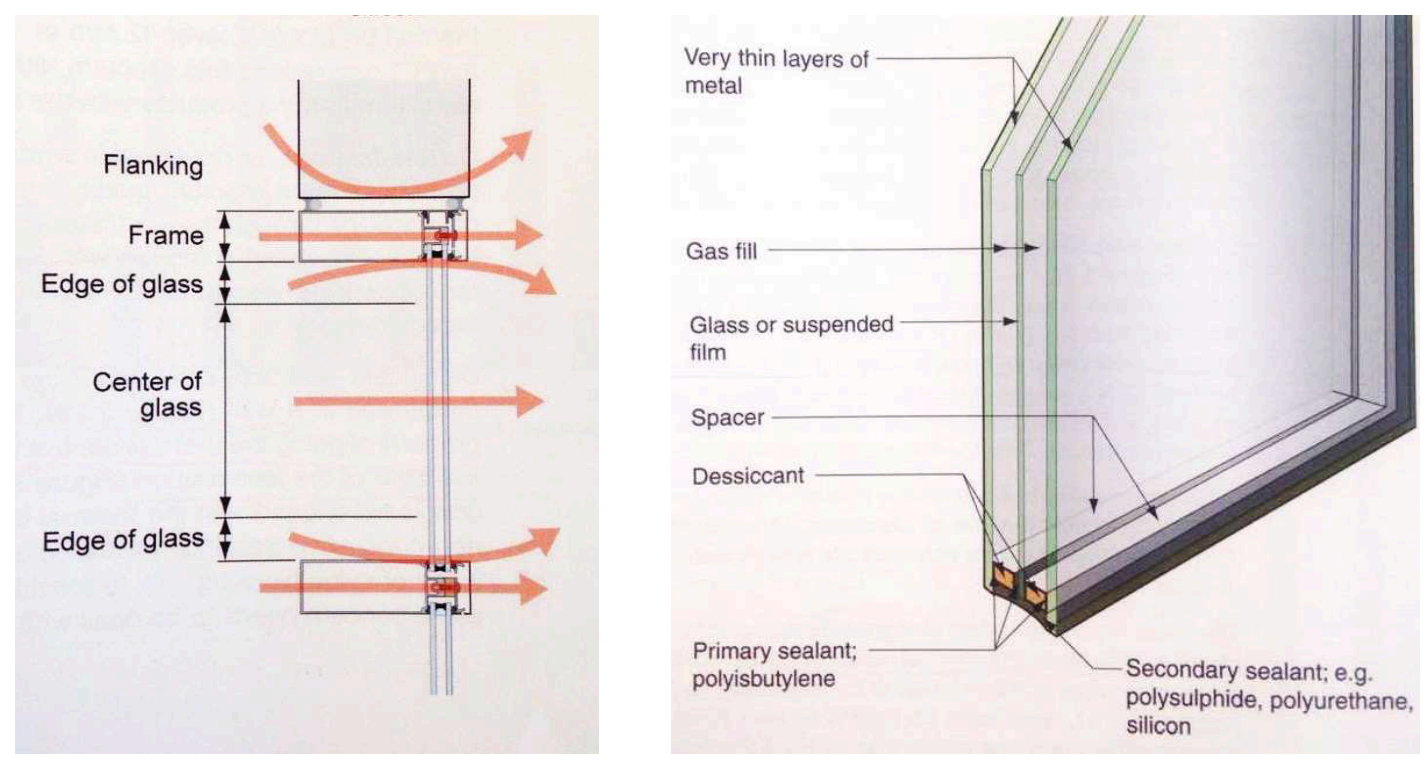

Figure 2.2: $\mathrm{U}$ value and heat loss through the edge and center of glass and frame.

There are three principles or modes by which thermal energy can be transfer; conduction, convection, and radiation. Conduction is most straightforward heat transfer mode in solid materials from higher temperature areas to lower temperature areas. Convection is; when fluid (such as air or liquid) is heated and then travel away from the source, it occurs because of differences in 
density. Radiation heat transfer takes place in the form of electromagnetic waves, does not necessarily require a medium to carry it.
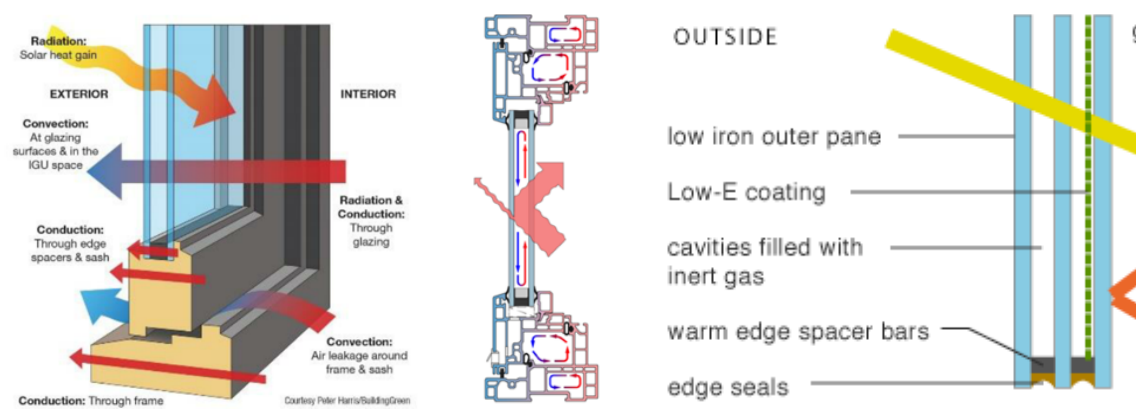

glass

INSIDE

hort wave radiation transmitted through the glass

Figure 2.3: Mechanism of heat transfer in windows (Source, RDH, 2017 and Internet).

As heat lost through the frames, the edge \& center of the glass and all three modes effect on heat loss, heat gain and energy performance, so it is also essential to understand the spectral properties of the glazing such as, Transmittance, Visible light transmittance (VLT), solar infrared and long wave infrared transmittance and how to control it.

\subsubsection{Spectral properties of the glazing}

Transmittance refers to the percentage of radiation that can pass through glazing. It also can be defined for different types of light or energy, e.g., Visible transmittance, UV transmittance, or total solar energy transmittance (CW, 2018).

Visible light transmittance (VLT) or Visible transmittance (VT), is an optical property that indicates the fraction of visible light transmitted through the window glazing or visible spectrum of sunlight (380 $\mathrm{nm}$ to $780 \mathrm{~nm}$ ), weighted by the sensitivity of the human eyes.

More than half of the sun's energy is invisible to the human eye (i.e. it falls outside the range from $380 \mathrm{~nm}$ to $780 \mathrm{~nm}$ ) and most reach us as near-infrared (above $780 \mathrm{~nm}$ ) with a few percents in the ultraviolet (UV) spectrum, below $380 \mathrm{~nm}$ (Iklimnet, 2018). Thus total solar energy transmittance describes how the glazing responds to a much broader part of the spectrum, and it is useful in characterizing the quantity of total solar energy transmitted by the glazing (AAAMSA, 2012). 


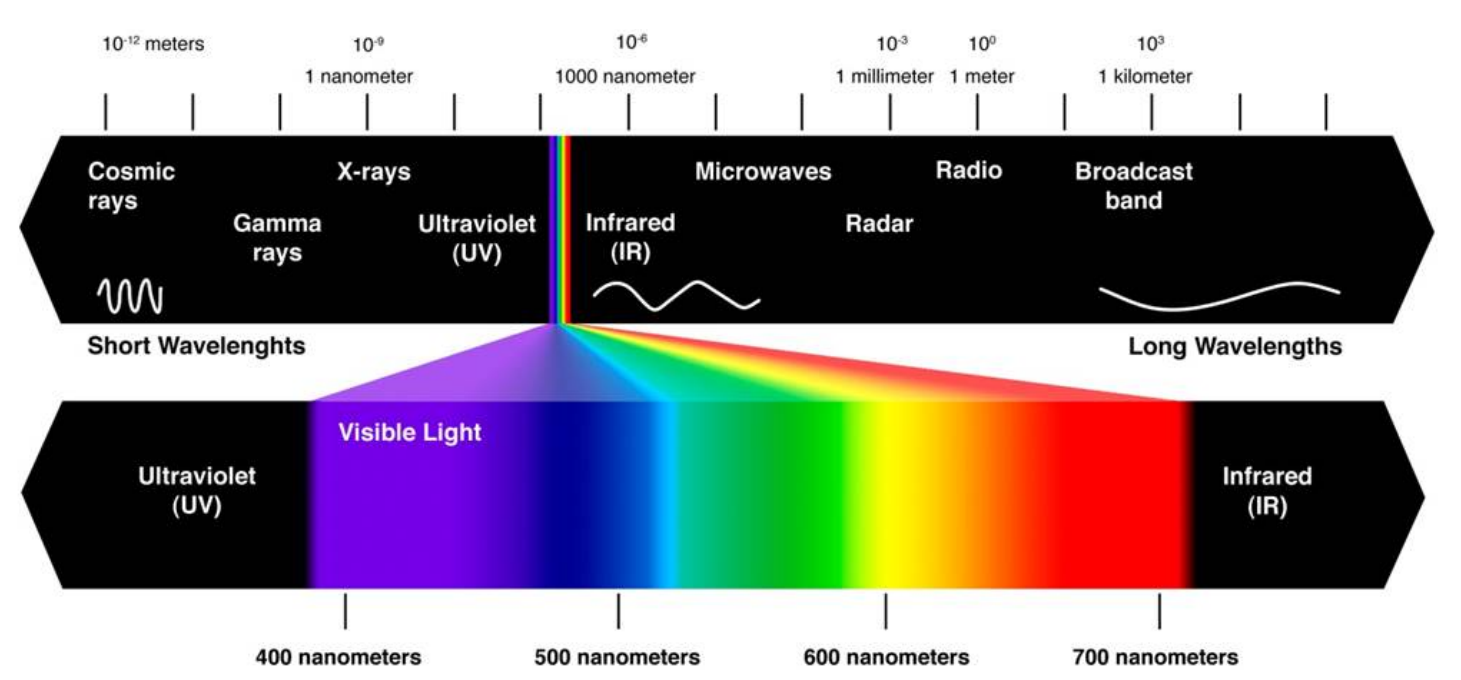

Figure 2.4: Visible spectrum and wavelengths corresponding to different colours.

In the recent advancement in glazing technology, manufacturers can control how glazing materials behave in the different areas of the spectrum, by changing the properties of the substrate material, altering through coatings that can be added to the surfaces of the substrates (AAAMSA, 2018). For example, a window glazing optimized for daylighting and reducing overall solar heat gains should transmit an adequate amount of light in the visible portion of the spectrum while excluding heat gains from the near infrared part of the electromagnetic spectrum $(\mathrm{CW}, 2018)$.

Following are the ideal spectral transmittance of glazing in different climates for different building loads as we typically target high transmittance in the visible range to have a clear view through the glass, while we can control rest of the spectrum in different ways and save energy.

1 Idealized transmittance of glazing with a low-E coating designed for low solar heat gain, where visible light is transmitted, and solar infrared radiation is reflected. Longwave infrared radiation is reflected back in the interior, and this approach is suitable for commercial buildings in almost all climates (AAAMSA, 2018).

2 Idealized transmittance of glazing with a low-E coating designed for high solar heat gain, where visible light and solar infrared radiation are transmitted. Longwave infrared radiation is reflected back in the interior, and this approach is commonly used for residential windows in cold climates (AAAMSA, 2018). 


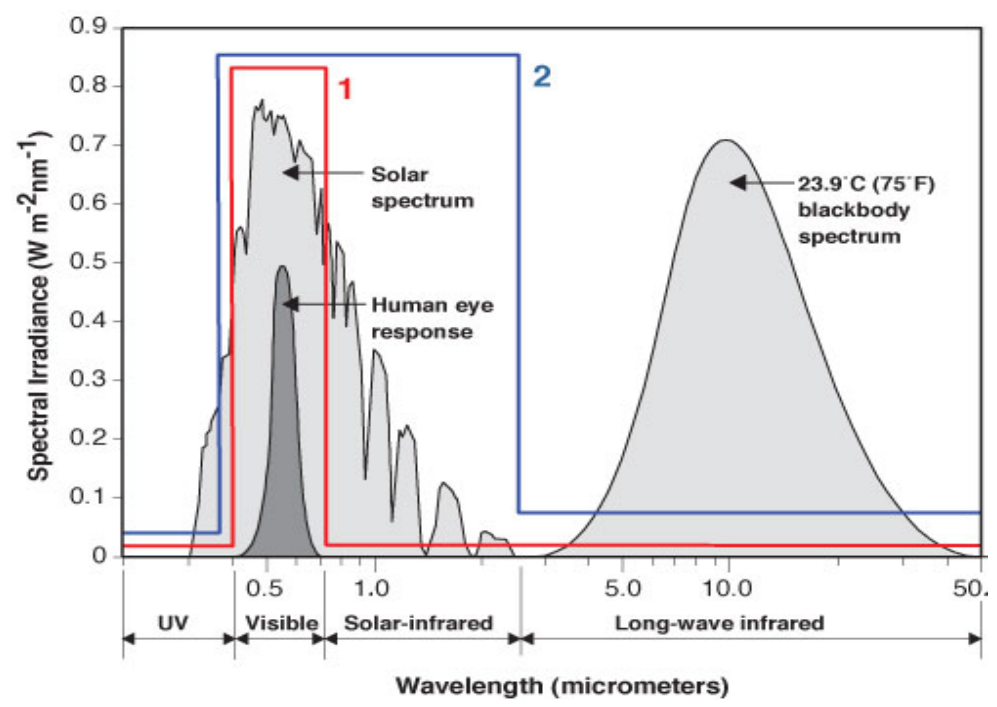

Figure 2.5. Ideal spectral transmittance for glazing (Source; AAAMSA, 2012)

\subsubsection{Solar Heat Gain Coefficient (SHGC)}

SHGC is a ratio indicating the amount of sun's heat that can pass through the glazing product (solar gain). SHGC is a number between 0 and 1 and the higher the number, the greater the solar gain. Products with an SHGC of less than 0.30 are considered to have low solar gain, while above this threshold are supposed to have a high solar gain.

Windows are the most important part of the building façade to control solar gain and thermal losses (Andrea, 2015). In a heating-dominated climate like Canada, windows with a low SHGC lead to lower cooling loads, but heating requirements are higher due to the loss of welcomed heat gains in the winter. In the past, windows that reduced solar gain with tints and coatings reduce visible transmittance, but new technology has made it possible to reduce solar heat gain with little reduction in visible transmittance $(\mathrm{CW}, 2018)$.

\subsubsection{The Energy ratings (ER)}

ER is a Canadian measure that evaluates the significant solar heat gained and heat loss through a window during winter heating season. Energy Rating is a dimensionless two-digit rating computed with a formula that includes the U-Value, SHGC and air leakage rate at a pressure difference of $75 \mathrm{~Pa}$ in $\mathrm{L} / \mathrm{s} \bullet \mathrm{m}^{2}$ as the input. The simplified ER equation is as follows (NRCan, 2018). 
$\mathrm{ER}=\left(57.76 \times \mathrm{SHGC}_{\mathrm{W}}\right)-\left(21.90 \times \mathrm{U}_{\mathrm{W}}\right)-\left(1.97 \times \mathrm{L}_{75}\right)+40$, Where Energy Rating $(\mathrm{ER})$ values can start from 10 or less

\subsection{Windows energy performance rating; Criteria and Standards}

Energy standards and certifications request high performance for transparent and opaque envelopes in buildings to minimize energy consumption (Mainini, Bonato, Poli, and Speroni, 2015). The focus of Canadian building code is to reduce winter season heating energy. Energy performance of windows is tested using the Canadian Standards Association (CSA) A440.2 standard and some products sold in Canada may also be tested using the criteria of the National Fenestration Rating Council (NFRC) in the United States (NRCan, 2018). Energy performance is rated using the values of $U$ factor, Solar heat gain coefficient (SHGC), Visible transmittance (VT), and Airtightness.

- NFRC 100 "Procedure for Determining Fenestration Product U-Factor

- NFRC 200 "Procedure for determining the Solar Heat Gain Coefficient and Visible Transmittance

CSA follows the NFRC simulation procedures, and the main difference between CSA A440.2 and NFRC 100 is that CSA allows $U$ values to be determined by simulation only (RDH, 2017) whereas, NFRC also requires physical testing to every five years.

Windows, doors and skylights sold in Canada may be certified for energy performance by any of these accredited agencies:

- CSA International (CSA)

- Intertek Testing Services (ITS)

- Quality Auditing Institute Ltd. (QAI)

- The National Fenestration Rating Council (NFRC) the U.S. based non-profit.

Both NFRC (100-2001) and CSA standards define U-Value under following environmental standard conditions; Winter design temperature $\left(-18^{\circ} \mathrm{C}\right)$, indoor temperature $\left(21^{\circ} \mathrm{C}\right)$ and outside wind speed $(5.5 \mathrm{~m} / \mathrm{c})$, to allow product comparisons. 
Many countries have developed energy performance rating systems of the glazing product based on the thermal transmittance (U value), solar heat gain coefficient (SHGC), and visible light transmittance (VLT) to manage the energy flow and encourage consumers to use high energyefficient windows. Nevertheless, the rating systems are more appropriate for new buildings, because older buildings mostly have heat gain values exceeding the regulation values, and replacement of window glass is fairly uneconomical. The trade-off solution is to adhere solar control films to glass windows to change the envelope thermal properties and in turn reduce the heat gain through the windows to meet the regulation value (Lee, Chen, Fan, Hsi, and Horng, 2014). Similar solution could be to improve thermal performance of the existing window glazing.

\subsubsection{ENERGY STAR Program in Canada}

Natural Resources Canada (2018) administers and promotes the use of the ENERGY STAR name and symbol in Canada under an agreement with the U.S. Environmental Protection Agency (EPA). ENERGY STAR has helped push better technology to mainstream markets (Selkwitz, 2017) for high-efficiency windows. Below image shows the energy star zone in Canada (NRCan, 2018).

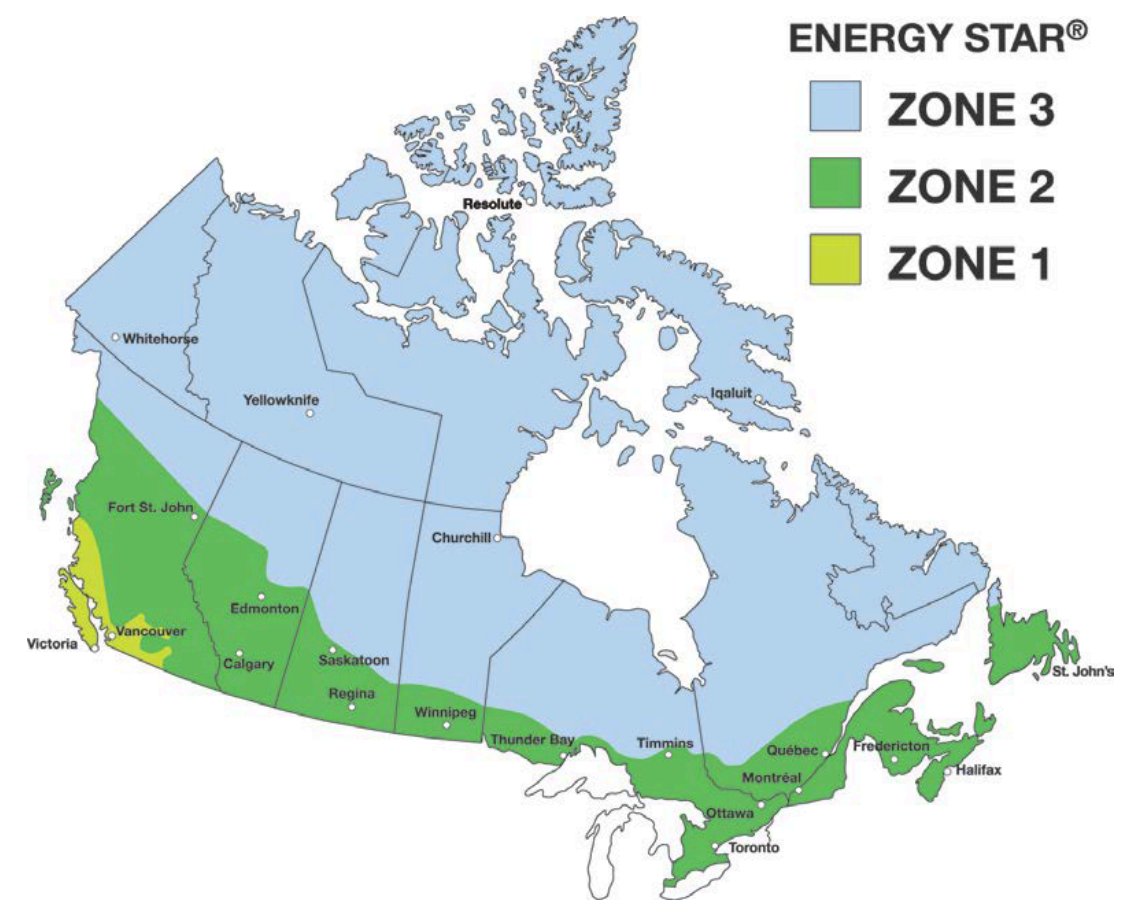

Figure 2.6: Climate Zone, Canada, found in the Model National Building Code, 2010. 
The climate zones are determined by heating degree day (HDD). Zone 1 is the warmest and 3 is the coldest. ASHRAE 90.1-2007: climate zones standard walls and R-Values will be considered during simulation study in the COMFEN 5 for Canadian locations.

\begin{tabular}{|l|l|l|l|}
\hline $\begin{array}{l}\text { ENERGY STAR } \\
\text { Zone }\end{array}$ & $\begin{array}{l}\text { Maximum U-factor } \\
\mathrm{W} / \mathrm{m}^{2} . \mathrm{K}\left(\mathrm{Btu} / \mathrm{h} . \mathrm{ft}^{2} .{ }^{0} \mathrm{~F}\right)\end{array}$ & $\begin{array}{l}\text { Minimum Energy } \\
\text { Rating Unitless }\end{array}$ & $\begin{array}{l}\text { Maximum Air } \\
\text { Leakage L/s/m }\end{array}$ \\
\hline Zone 1 & $1.60(0.28)$ & 16 & 1.5 \\
\hline Zone 2 & $1.40(0.25)$ & 20 & 1.5 \\
\hline Zone 3 & $1.20(0.21)$ & 24 & 1.5 \\
\hline
\end{tabular}

Table 2.1: Windows qualifying criteria for ENERGY STAR; Source Narcan, 2018

Every ENERGY STAR certified window, door and skylight are required to leave the factory with a removable tag that shows (NRCan, 2018):

- Its certified performance ratings (U-factor, Energy Rating, etc.)

- The climate zone(s) for which it is certified

- A description of the product (type, materials, glazing, etc.)

- Its certification information
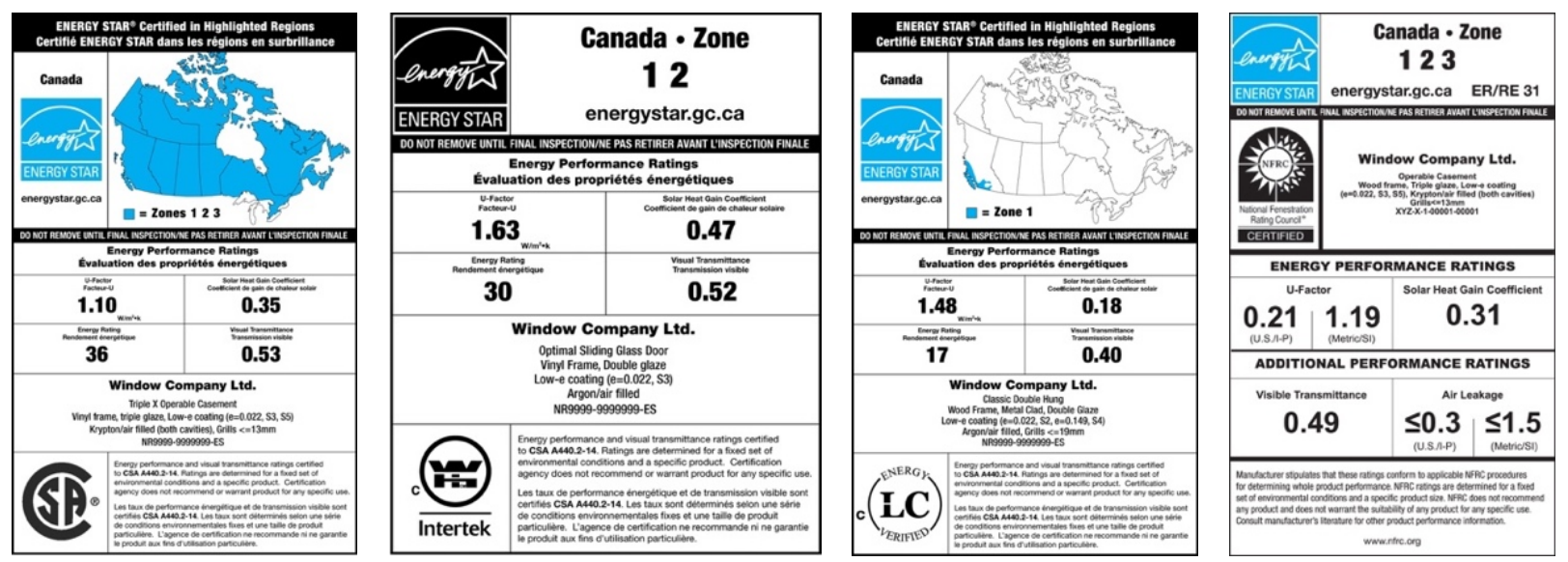

Figure 2.7: Example of Energy Star Labels, Key features, Certification, Climate Zones

\subsubsection{Coated Glazing Properties Measurement}

According to the Lawrence Berkeley National Laboratory (LBNL) for the coated glazing, measurement of transmittance and reflectance should be made over the solar spectrum (from 
$300 \mathrm{~nm}-2500 \mathrm{~nm}$ wavelength) using a commercial spectroradiometer equipped with a proper integrating sphere following NFRC 300 (LBNL, 2018). LBNL also indicates the reflectance in the thermal infrared must also be measured from at least 5-25 micron following NFRC 301. A default value may be used for the emissivity for known materials such as transparent or uncoated glazing. The glazing coating considers for this study tested in the Ryerson university laboratory following the above standard and procedure.

\subsection{State of the art window technology}

The following technological improvements and techniques may help to achieve windows performance goals discussed above. For instance, aluminum frames with polymer thermal breaks, fibreglass and vinyl frame hollow sections filled with foam insulation and solid wood frames protected from weather and combination of materials to reduce heat loss through the structure. Besides frames, the most significant advantages in the energy performance of the window is glazing technology that includes; IGU (multilayer of glass) filled with gas, warm spacers and LowE coating that helps reducing heat loss.

Heat loss through the window can further be reduced by filling the gap between the panes of glass units with gas like argon, krypton having a density higher than that of air from warm pane to cold pane by convection. It is often termed inert gas that prevents chemical reaction and reduces undesirable visual obstruction.
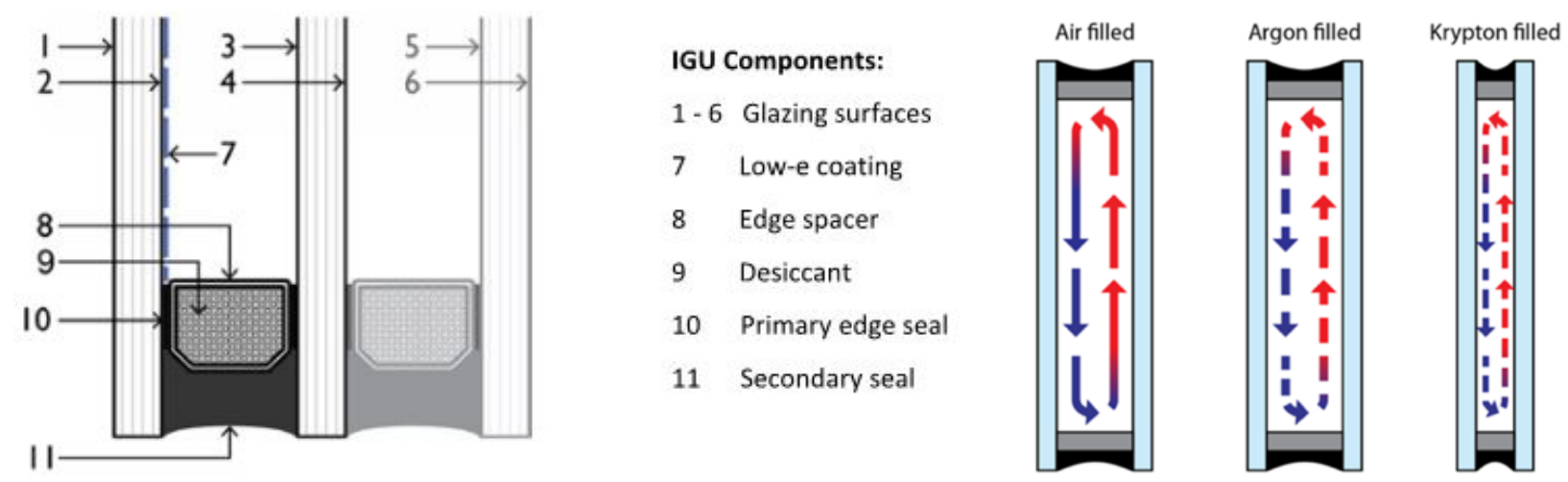

Figure 2.8: Typical components of IGU and Low conductance gas fills (RDH, 2017) 
The term "warm-edge spacer" is often assuming to describe spacers that have no metal and conducts less heat than convention aluminum spacers, for example, stainless steel spacers minimize heat transfer.

Heat Mirror technology is a nanoscale coating of metal to reflect heat to its source. It suspends one or more lightweight films inside the airspace of an insulating glass unit to create multiple "superinsulating" chambers. Depending on the number of films and the type of inert gases added within, insulating glass made with Heat Mirror technology can have an R-value from 6 to 20, which can insulate as well as typical walls (Eastman, 2018).

Three panes or two panes IGU and suspended film, outperform ENERGY STAR criteria but present market share only around $2-3 \%$. However, the application of these advanced glazing systems requires reconstruction for existing buildings, which may cause disturbance to the occupants (Li, Tan, Chow, and Qiu, 2015). Existing windows need different approaches to improve energy performance.

\subsection{Energy Efficiency in Window; Facts and Myths}

As windows is a long-term investment, before making any change need to assess existing conditions and options. Following are the four basic options for the energy efficiency of windows (NRCan 2011).

- Repair: If the window appears to be in good shape, it may be possible to improve airtightness by repairing or replacing the sash locks, hinges for example.

- Re-glaze: Installing exterior or interior storm windows

- Replace: Replace the whole window or parts of the window.

- Retrofit: Addition of the new technology or features to the existing or older systems. In the window retrofit using caulking, weather stripping, adding films or coatings etc. on glazing could be options.

Replacing the current window is the best way to cut energy loss and save money if cost or historical values are not considered. Installation of secondary glazing (or storm windows) can involve the internal addition of the second pane of glass or plastic to existing single-glazed windows to 
improve the thermal performance of windows during the heating season, without the need to remove the existing glazing (Smith, Isaacs, Burgess, and Cox-Smith, 2012). Study also has found, the R-value for the secondary glazing systems are more than twice the R-value measured for the base window, that is even better than the values claimed by the manufacturers for their various secondary-glazing systems, though the manufacturers do not provide details of their calculation methods or assumptions. The main reason for the higher R-values is the glazing pane separating the frame from the interior air and there is no conductive heat loss like standard glazing. However, a report by The National Trust for Historic Preservation, states that "retrofit strategies come very close to the energy performance of high-performance windows replacement at a fraction of cost (Spurce, 2018). If windows are in good condition, taking technical steps to improve efficiency may be the most cost-effective way and to increase comfort and save money (DOE, 2018). So, this study concentrated on windows retrofit options.

\subsection{Windows energy retrofit guidelines}

Though heating requirements rather than cooling, dominate all of the climate zones in Canada but due to warmer condition during summer solar admission also need to be block for the occupant comfort, so windows should be updated with the following criteria.

- Minimize heat loss: Selecting the lowest U-value of window glazing.

- Minimize window emissivity: Choosing a low emissivity (Low-E) glazing to minimize heat radiated through the window.

- Control solar heat gain: The solar heat gain coefficient (SHGC) can be controlled from one side (south-facing of 0.6) to another side (east-west of 0.25 ) for occupant comfort during the early and later parts of the day.

- Maximize visible light transmittance: TVIS, for daylight.

\subsubsection{Improve glazing products}

There are three fundamental approaches to improving the energy performance of glazing products (Window, 2013): 
- Glazing material can be altered by changing its chemical composition or physical characteristics. An example of this is tinted glazing.

- Application of a film or coating to the glazing surface can reduce heat gain and glare. Lowemittance and spectrally selective coatings improve both heating and cooling season performance.

- The use of two or more panes, low-conductance gas fills between the layers and thermally improved edge spacers.

These approaches may be combined to improve the glazing performance.

Windows retrofit film or coating have a much less complicated and less expensive installation than a complete window replacement. The attachment of solar window film on glazing is able to control light and heat penetration and to filter out Ultra-Violet (UV) light, whilst causing the least influence on the building users (Li et al., 2015).

Mainini et al., (2015) explored different retrofit strategies for transparent envelope of the existing office buildings to improve their performance and to ensure low energy use. As solar and light control is necessary to prevent overheating in office buildings, so solar window films were investigated in comparison with other strategies like the use of internal roller blinds and existing window pane substitution for that context. Results indicated solar films were more effective in reducing primary energy for cooling but determine an increase in primary energy use for heating and lighting, due to the reduction in visible transmittance.

Moretti, and Belloni, (2015) claimed, a suitable way to change the properties of glass windows is to use solar control films, which could be applied to existing glazing's in order to modify their lighting and thermal properties, especially in moderate or hot climates. A non-residential building was investigated for this purpose that built with high window-to-wall ratios due to aesthetic reasons and in order to encourage daylighting for energy savings but heat gain from the windows contributed significantly to the building envelope cooling load. The building performance was deeply investigated by energy simulation tools and the results showed a decrease in SHGC by 44\% when film applied to the external side of existing windows; whereas the reduction was $22 \%$ for application on the internal side. Another study in an apartment building in Mexico was investigated 
by Energy-10 software and found the yearly energy consumption is reduced up to $16 \%$ for a room with a solar control film applied to a simple glass. Solar control films could be a suitable way to reduce cooling energy consumptions and to reduce discomfort conditions in existing glazed buildings (Moretti, and Belloni, 2015). The attachment of solar window film on glazing is able to control light and heat penetration and to filter out Ultra-Violet (UV) light, whilst causing the least influence on the building users (Li et al., 2015).

It is essential to recognize the right options, for example, solar control film reduces solar gain and saves cooling energy but also contribute to increase heating energy consumption in winter, so annual energy performance of the retrofit for the building and climate must be considered. There is also some low-e film available, building owners using to improve thermal performance of their old building windows in cold climate. The study also indicated that two factors significantly influence the effect of the window film; the position of the installed window film and the configuration of the original glazing system (Yin, Xu and Shen, 2012). Application with curtain wall performance varies due to the type of film and how it is applied. The building cooling and heating load through the windows on design day is also varies due to film application on outside and inside separately. Adding the window film inside of the curtain wall was not effective because the increased window conductive heat transfer offsets the decreased cooling load from solar radiation (Yin et, al, 2012).

One of the biggest downfalls of solar control film would be the lack of natural light penetration; traditionally speaking, the more a window film is efficient, the more it will darken a room. Most of the film available have a life expectancy of 8 years and being exposed to sunlight; the film will typically start to discolour, peel, dry, crack, form bubbles and lose its initial effectiveness (Sketchnano, 2018). The coating that can be used at the interior side of the existing window glazing can be an excellent option to avoid suns exposure and to reduce the winter heat loss. The reflective thin film coating limit absorption of infrared radiation within the glass pane reflect long wave infrared radiation back to building interiors and reduce radiation heat losses of glazing's (Mohelnikova, 2009). There are some nano coatings available in the Canadian market blocks up to $100 \%$ of UV rays. Minimize the infrared penetration, allows to control heat loss in the winter 
by creating a thermal barrier and controlling its solar heat gain coefficient (SHGC) properties can reduce the cooling loads in summer.

\subsubsection{Coating on window glazing}

Coatings on window glazing can have a meaningful impact on building heating and cooling loads. The performance of these coatings is typically discussed regarding two related metrics: emissivity and solar heat gain coefficient. (NRCan, 2014).

Emissivity is the ability of a material to radiate energy (Vitro, 2018). All elements including windows glazing emit or radiate heat, that can significantly improve its insulating properties, for example, standard clear glass has an emittance of 0.84 , meaning that it emits $84 \%$ of the energy possible and reflects only 16\%. By comparison, low-emissivity (low-E) glass coatings can have an emittance as low as 0.04 , emitting only $4 \%$ of the energy and reflecting $96 \%$ of the incident long-wave, infrared radiation. Low emittance reduces heating losses in the winter by reflecting heat into the building and reduces cooling loads in the summer by reflecting heat away from the building (NRCan, 2011).

Adding thermal coating on existing glazing provide an invisible thermal shield and prevents the heat escaping from the building through windows. These coatings operate as mirrors for longwave infrared radiation of building interiors (Mohelnikova, 2009). Some glazing coatings can block as much as $66 \%$ of the sun's heat to the building allowing to run air conditioning system less frequently can lower the costs by up to $40 \%$ (CG, 2018).

The coating can be optimized to reflect and, in that way, to reduce the transmission of higher frequency solar radiation that contributes to overheating the building ( $\mathrm{RDH}, 2017)$. Coating affects the amount of visible light transmitted through the coated glass as the surface is more heat reflective, the less visible light transmits. Coatings that control the passage of long-wave solar radiation in the different ranges, through transmission and reflection, contribute significantly to energy savings have been the subject of significant innovations in recent years (Berardi, 2017). Coating can be located on different glass surfaces in the IGUs, shown below. 


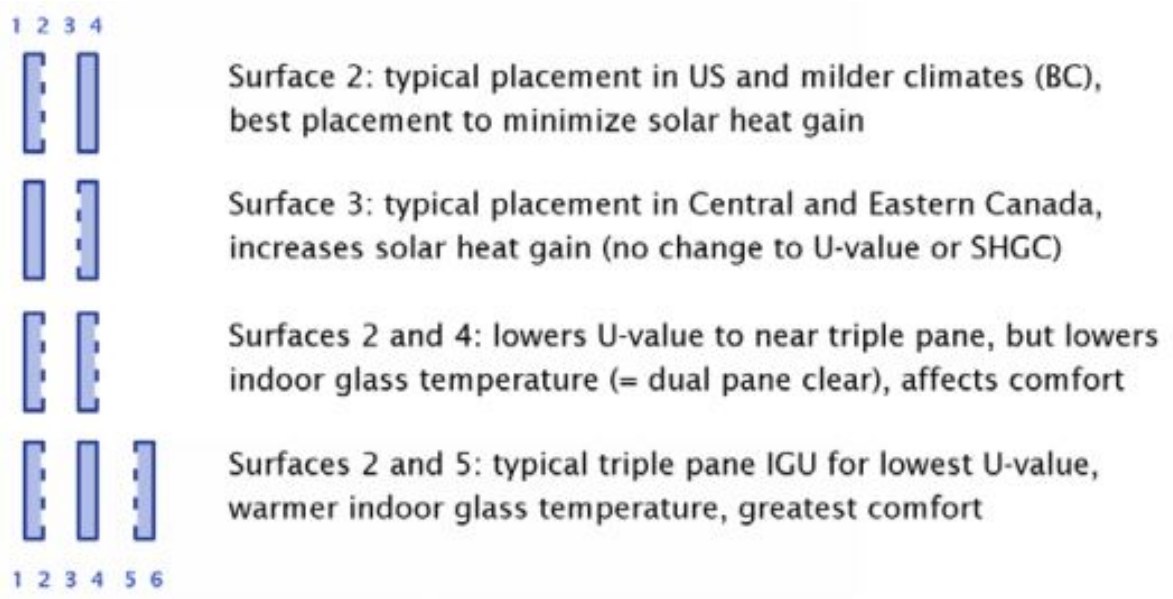

Figure 2.9: Typical Low-E coating position on the glass surface; Source RDH, 2017

Low-E coatings are applied to the various surfaces of insulating glass units (IGU's) during manufacturing process. Sketch NanoGard SC (SNG-SC) liquid coating is designed for use to the interior side of the existing window glazing.

Typically, U-Value, Visible Light Transmittance (VLT), Solar Heat Gain Coefficient (SHGC) are used to measure the effectiveness of coating or coated glass.

\subsection{Research \& Development}

Which coating would be best for windows retrofit at the local condition? Depends on the annual energy performance and return on investment. So many people and organizations in the globe contributed their time, expertise, and guidance to develop program direction for high-performance windows and glazing's technologies, systems and tools.

Many tools have been introduced and developed to analyze building products, components, environmental factors or even whole buildings. Followings are some tools, developed by Lawrence National Berkeley Laboratory (LBNL), helps building professionals for research and development.

Product Design: $\quad$ WINDOW, THERM, Optics, etc.

Façade Design: $\quad$ COMFEN (Whole Building Commercial), RESFEN (Whole Building, Residential) 
Daylighting: $\quad$ Radiance

Glazing Database: $\quad$ IGDB (Specular glass data),

CGDB (Complex glazing data)

Whole Building: $\quad$ Energy Plus with new GUI.

Many state of the art software tools have been developed to investigate the building and its components performance issues. COMFEN is one of them and has been selected for this study to look at the energy performance benefit of the SNG-SC coating for the systematic evaluation of alternative fenestration design for the project-specific building applications in the Canada Context.

\subsection{COMFEN; An early design tools for retrofit analysis}

Though new construction is finally improving, retrofit remains an important target for the owners, so COMFEN is introduced to identify performance drivers for the existing design and explore the impact of different retrofit strategies to energy performance. Especially, to make informed decisions about building fundamentals that provides a starting point for the project teams evaluating the performance of existing buildings (LBNL, 2018).

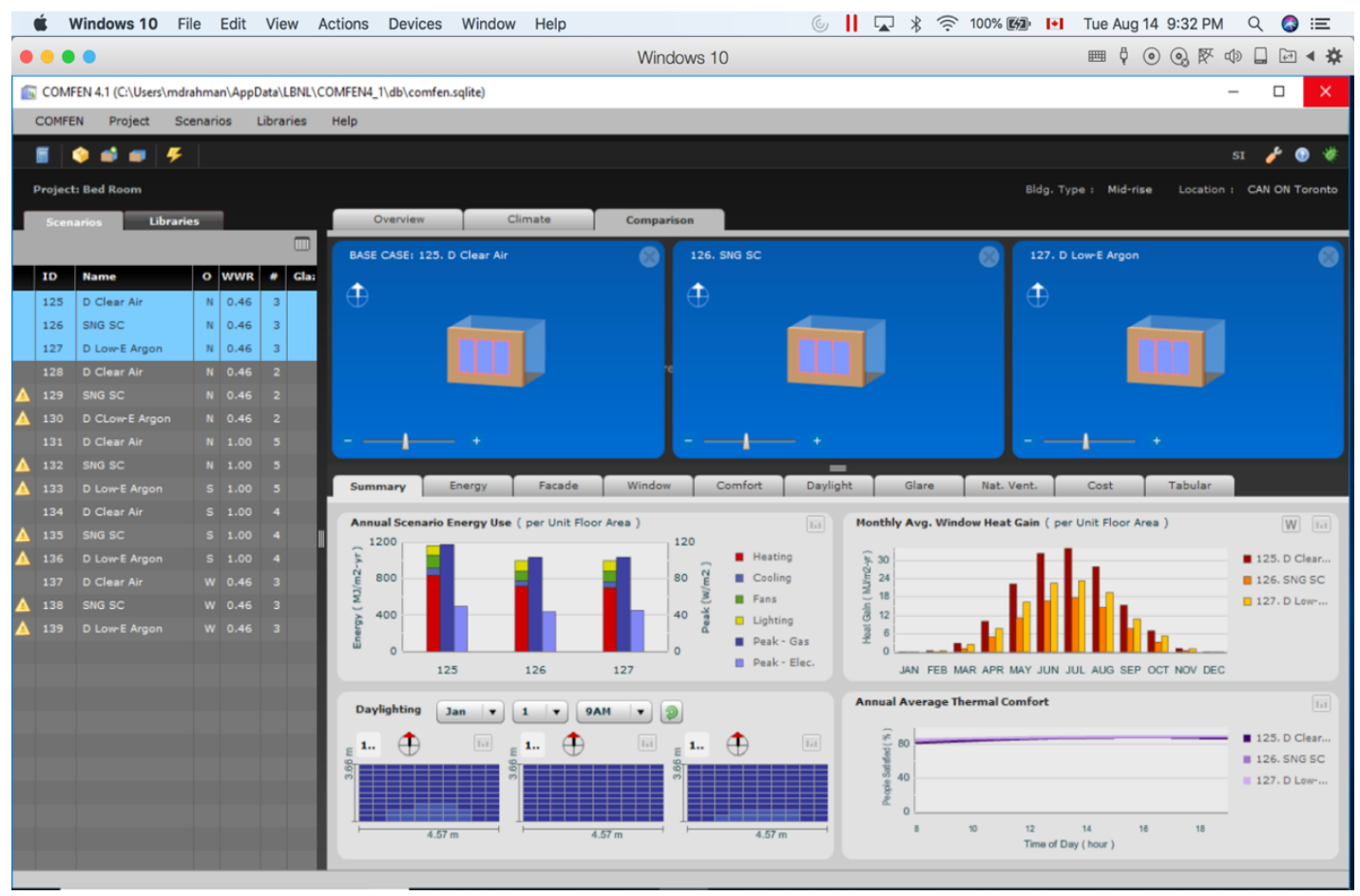

Figure 2.10: Overview of the COMFEN program interface. 
It supports the systematic evaluation of alternative fenestration systems for project-specific commercial building applications, and a simplified user interface focuses on critical variables in fenestration design. Energy Plus, simulation engine simulates the effects of these key fenestration variables on energy consumption, peak energy demand, daylighting, thermal and visual comfort. Easily define fenestration façade details include windows, size, placement, glazing, frame system, and exterior shading by overhangs and fins. Each facade can optionally include daylighting controls, compare the variations and can be oriented to different face directions.

Comparative charts are displayed for annual and monthly energy consumption (heating, cooling, fan, and lighting), peak energy, and $\mathrm{CO} 2$ emissions. Average daylighting illuminance, glare index, and thermal comfort also reported for monthly and yearly.

One perimeter "zone" or "room" is modelled in the program, rather than a whole building allows the program simulation to run much faster and will give results that are appropriate for this level of design analysis. The exterior façade of the zone is the only surface that is exposed to the outside environment, and all other surfaces are adiabatic, so there is no heat loss modelled through those surfaces.

It provides the ability to import glazing systems that have developed in Window. A single HVAC system type (packaged single zone), is currently available.

Energy Plus and Radiance engines are used in the program and a simple, graphic user interface to allow the user to explore the effects of changing critical early-design input variables for the façade.

\subsubsection{Cost Calculation; Simple Pay Back and Analysis}

A simple cost model is incorporated into COMFEN to compare the economic feasibility of different scenarios from the ASHRAE documentation data of the building components, i.e, glass layers, gases, frames, glazing systems, shading systems, window systems, HVAC system, lighting and lighting controls. All costs listed throughout the COMFEN interface include material and labour cost and a $30 \%$ markup to account for contractor and subcontractor costs. 
After total project cost has been calculated, it is multiplied by a location-specific adjustment factor to account for variation in construction costs (Mitchell, Yazdanian, Zelany, and Curcija, 2012). The resulting value is called the "Adjusted cost", since this adjustment is location-specific, none of the component costs in the libraries are adjusted. Energy-efficiency strategies in buildings often evaluated regarding their economic feasibility. One such measure is the simple payback; the amount of time (usually in years) required to recover the initial project cost is an opportunity. For example, simple payback can be used to calculate the time it will take for cost savings. The payback calculation in COMFEN only takes into consideration the annual energy savings of the scenario.

COMFEN use the following formula for the payback calculation:

Payback $($ years $)=\left(\mathrm{FC}_{\text {Case } 1}-\mathrm{FC} \mathrm{BC}\right) /\left(\mathrm{EC}_{\text {Case }} 1-\mathrm{EC}_{\mathrm{BC}}\right)$, Where,

$\mathrm{FC}_{\text {Case } 1}$ - The first cost of the scenario.

$\mathrm{FC}_{\mathrm{BC}}-$ First cost of the base case (reference) scenario.

EC Case 1 - The energy cost of the scenario.

$\mathrm{EC}_{\mathrm{BC}}-$ Energy cost of base case (reference) scenario. 


\section{SKETCHNANOGARD (SNG-SC) COATING}

Sketch NanoGard SC (SNG-SC) is a window coating designed for the interior surface that reduces ultraviolet (UV) and infrared rays (IR) transmittance while being transparent to light transmission.

\subsection{Advantages and benefits}

According to the technical data sheet following are that the advantages and benefits.

- It reduces heat gain in the summer and heat loss in the winter.

- It has a little impact on visible light transmission (VLT).

- It reduces the impact of harmful UV.

- It reduces condensation.

- It shows high resistance to harsh Canadian climate.

\subsection{Applications}

The application consists of applying $25 \mathrm{~g}$ of product per square meter with a special density foam roller to obtain optimal coating thickness of 8-10 microns. If needed, the SketchNanoGard-SC coating can be removed by qualified technicians. Details are following.

1) Use roller diagonally. Apply initial pass by making an " $X$ " pattern.

2) Make four (4) vertical passes.

3) Make two (2) horizontal passes.

4) Make 1 horizontal pass (width of the sponge roller) completely at the top of the window from left to right and right to left.

5) Make one (1) vertical finishing pass (Lip-out)

6) Estimated application time: 3-7 minutes per 20 sq. feet depending on glass temperature. 

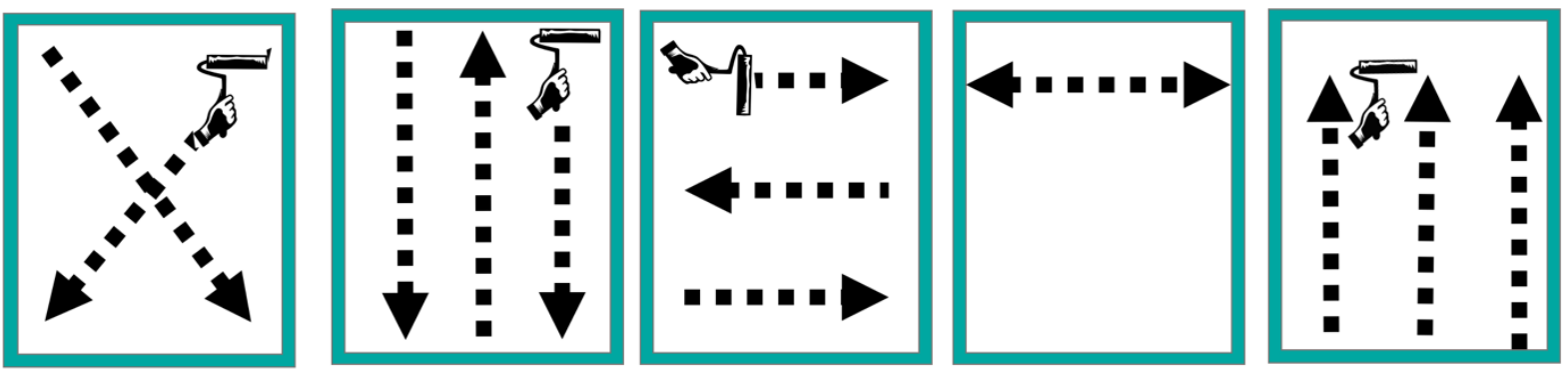

Figure 3.1: SNG-SC coating application techniques.

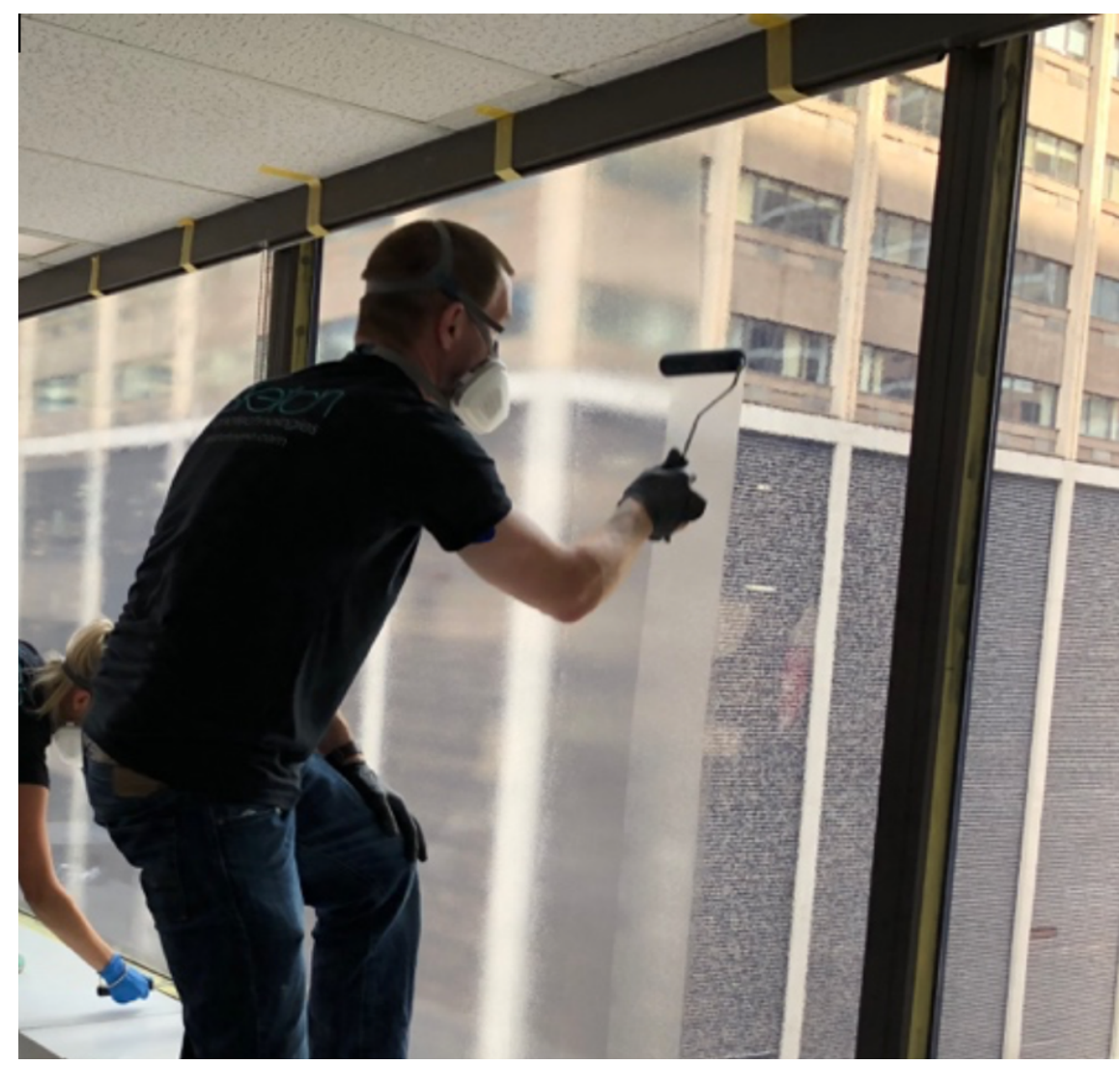

Figure 3.2: SNG-SC coating application on the glazing surface. 


\section{RESEARCH METHOD}

The research methods comprised of the steps updated in figure 4.1.

\section{Energy Performance Modeling, Simulation and Analysis}

\begin{tabular}{|c|c|c|c|c|c|}
\hline $\begin{array}{l}\text { Sample } \\
\text { Glass } \\
\text { LAB Data } \\
\text { (Thickness } \\
\text { Conductivity } \\
\text { IR Trans } \\
\text { Solar trans } \\
\text { Solar reflect }\end{array}$ & $\begin{array}{l}\text { Formatted LAB } \\
\text { test data } \\
\text { according to } \\
\text { IGDB file } \\
\text { format. }\end{array}$ & $\begin{array}{l}\text { Imported } \\
\text { notepad data. } \\
\text { Determined } \\
\text { spectral data. } \\
\text { Created user } \\
\text { database. } \\
\text { Generated } \\
\text { Transmittance } \\
\text { curve. }\end{array}$ & $\begin{array}{l}\text { Imported spectral } \\
\text { data from Optics } \\
\text { Calculated glazing } \\
\text { (single) properties } \\
\text { Modeled double } \\
\text { glazing systems } \\
\text { Calculated double } \\
\text { glazing systems } \\
\text { properties }\end{array}$ & $\begin{array}{l}\text { Modeled room } \\
\text { \& windows (WWR) } \\
\text { Imported double } \\
\text { glazing system } \\
\text { data from window } \\
\text { Applied those } \\
\text { data to scenarios } \\
\text { Run simulation } \\
\text { Calculated } \\
\text { payback period }\end{array}$ & $\begin{array}{l}\text { Edited } \\
\text { COMFEN results } \\
\text { Displayed in } \\
\text { tabular } \\
\& \text { graphical } \\
\text { format } \\
\text { Analyzed results }\end{array}$ \\
\hline Collection & Notepad & Optics & Window & COMFEN & Excel \\
\hline
\end{tabular}

Figure 4.1: Overview of the research method.

Data collection involved to find the following information of the $6 \mathrm{~mm}$ SNG-SC coated glass:

- Thermal conductivity

- IR Transmittance

- Solar transmittance

- Solar reflectance

- Appearance

\subsection{Energy Performance Modeling, Simulation and Analysis}

The research involved using some software such as Optics, Window and COMFEN from Lawrence Berkeley National Laboratory (LBNL) to process and apply those LAB data to the proposed scenarios (room) and windows (fixed, operable and curtain wall) for the energy performance modelling, simulation and analysis.

\subsubsection{Data formatting}

Notepad was used to create a complete and detail specification of the general file format of the SNG-SC coated glazing product according to the international glazing database (IGDB) system. Data format includes the product name, manufacturers name, wavelength units, thickness, thermal 
conductivity, IR Transmission, emissivity, appearance, structure and spectral data (light transmittance) of the sample glass. A sample of the detail file format is shown in figure 4.2.

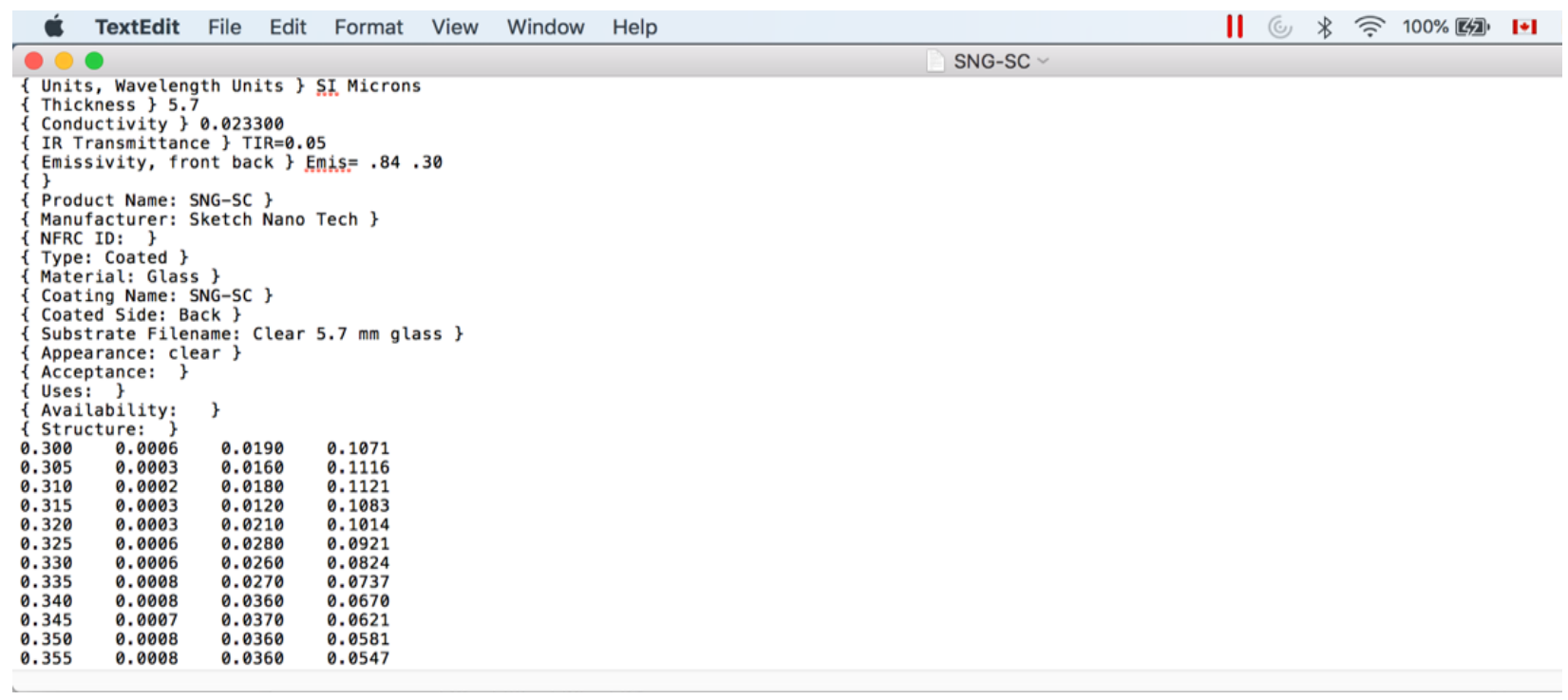

Figure 4.2: IGDB general file format.

\subsubsection{Craeted a user database and transmittance image}

The Optics computer program was used to help, manipulating optical layers and calculating spectral data for glass and glazing layers. Notepad made it easy to import test data into Optics according to the IGDB format rules and determined the spectral data such as solar and daylighting properties (Tvis, Tsol, Rvis, Rsol) and transmittance curve. It also created "user database" to export constructed data for use with the Berkeley lab Window. Calculated spectral data and transmittance image are reported in figure 4.3.
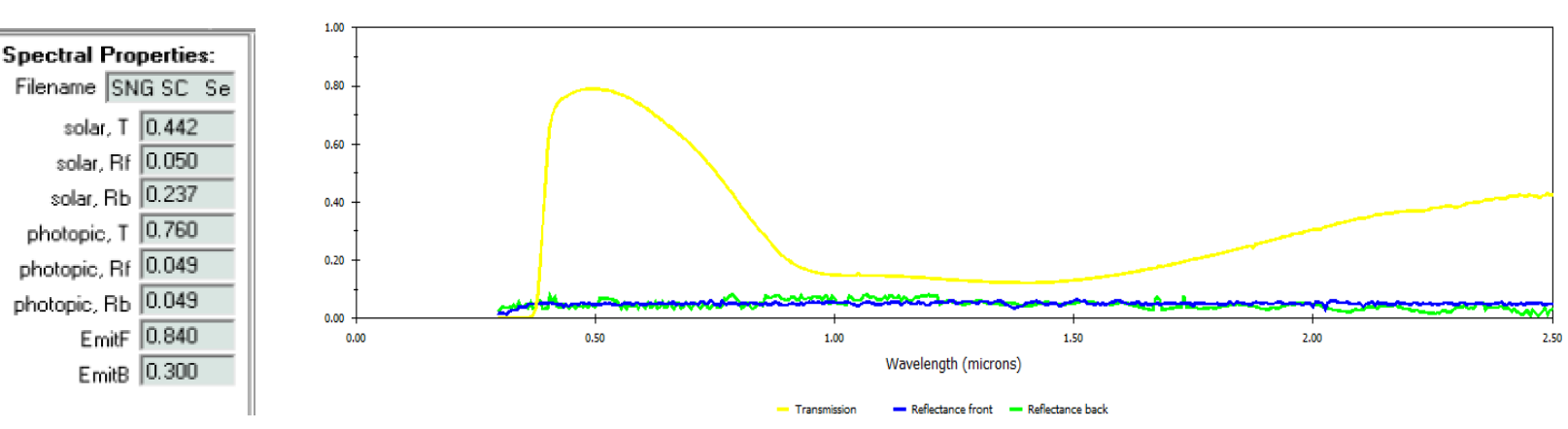

Figure 4.3: Spectral data and transmittance image (curve) generated in Optics 


\subsubsection{Glazing systems modelling and calculation}

Window program was used for calculating thermal performance properties; (i.e. U-factor, SHGC and visible transmittances; VT) of the glazing and glazing systems (IGUs). The SNG-SC coated glazing spectral data imported from Optics user database through Window glass library and calculated its (single glazing) properties first. Calculated results are reported in table 4.1.

\begin{tabular}{|l|l|l|l|}
\hline Single glazing & TVis & SHGC & U-Factor $\left(\mathrm{W} / \mathrm{m}^{2} . \mathrm{K}\right)$ \\
\hline 6 mm clear glazing & 0.884 & 0.818 & 5.818 \\
\hline SNG-SC coating on 6mm clear glazing & 0.760 & 0.614 & 2.547 \\
\hline
\end{tabular}

Table 4.1: Single glazing (clear and coated) properties calculated in Window

When data introduced to Window, it also offers the ability to analyze products made from any combination of glazing layers, gas layers, frames, spacers, and dividers under certain environmental conditions. Three glazing systems; double clear air (base case scenario), SNG SC coating on double clear air and double low-E argon glazing systems have been considered for this study (table 4.2).

Glazing systems 1 and 2 were modelled and calculated their properties in Window considering NFRC 100-2010 standard environmental conditions. Glazing system 3 selected form COMFEN glazing library as default to compare with other two systems. The compositions and properties of the three glazing systems are reported in table 4.2 and table 4.3 .

\begin{tabular}{|l|l|l|}
\hline No & Glazing Systems & Glazing Layers $(6 \mathrm{~mm}$ glass $/ 12.5$ air gap/6 mm glass $)$ \\
\hline 1 & Double Clear Air & Clear/air/clear \\
\hline 2 & SNG-SC Air & Clear/air/ SNG-SC coated \\
\hline 3 & Double Low-E Argon & Low-E Coated/argon/clear \\
\hline
\end{tabular}

Table 4.2: Composition of the glazing layers

\begin{tabular}{|l|l|l|l|}
\hline Glazing Systems & TVis & SHGC & U-Factor $\left(\mathrm{W} / \mathrm{m}^{2 *} \mathrm{~K}\right)$ \\
\hline Double Clear Air & 0.786 & 0.704 & 2.689 \\
\hline SNG-SC Air & 0.674 & 0.572 & 1.869 \\
\hline Double Low-E Argon & 0.693 & 0.473 & 1.750 \\
\hline
\end{tabular}

Table 4.3: Glazing systems and properties. 


\subsubsection{Modelling and Simulation in COMFEN}

A standard representative room of a mid-rise residential building in Toronto was modeled in the COMFEN environment for this study. Then, three windows; fixed, operable and curtain wall systems with different window wall ratios (WWR) were proposed as an alternative fenestration design choice to estimate and compare their primary energy use under different weather conditions and envelope orientation. Typical details are as follows

- Room Geometry: Height=3.05m, Width=4.57 $\mathrm{m}$ and Depth=3.66 m (Figure 4.4)

- Window Types: Fixed and operable; Height $=02 \mathrm{~m}$, Width $=3.2 \mathrm{~m}$ (Figure 4.5)

- Curtain Wall: $\quad$ Height $=3.05 \mathrm{~m}$, Width $=4.57 \mathrm{~m}$ (Figure 4.7)

- Frame Materials: Aluminum

- Window Wall Ratio (WWR): Fixed and Operable window; 0.46, Curtain wall; 1

- Wall Assembly: ASHRAE 90.1-2007: climate zones standard walls and RValues considered during simulation study.
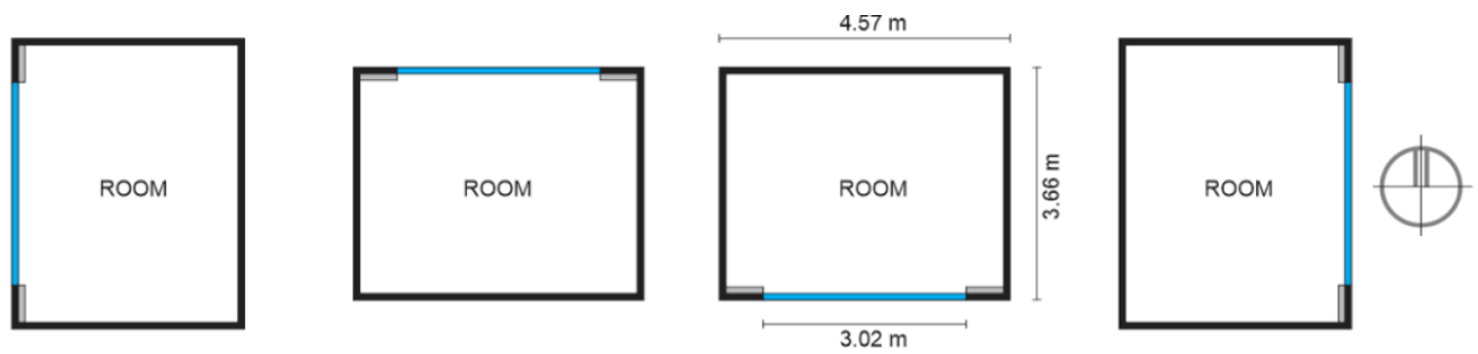

Figure 4.4: Proposed room and windows plan with different orientations.
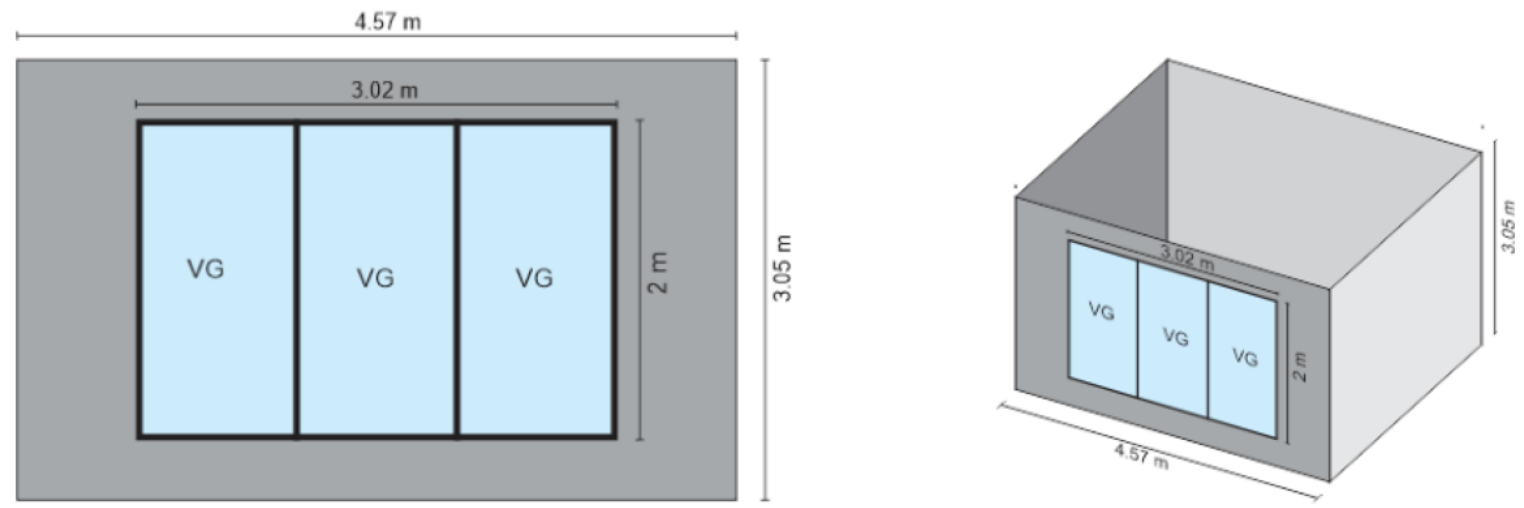

Figure 4.5: Fixed Window: Overview of model (elevation and isometric view). 

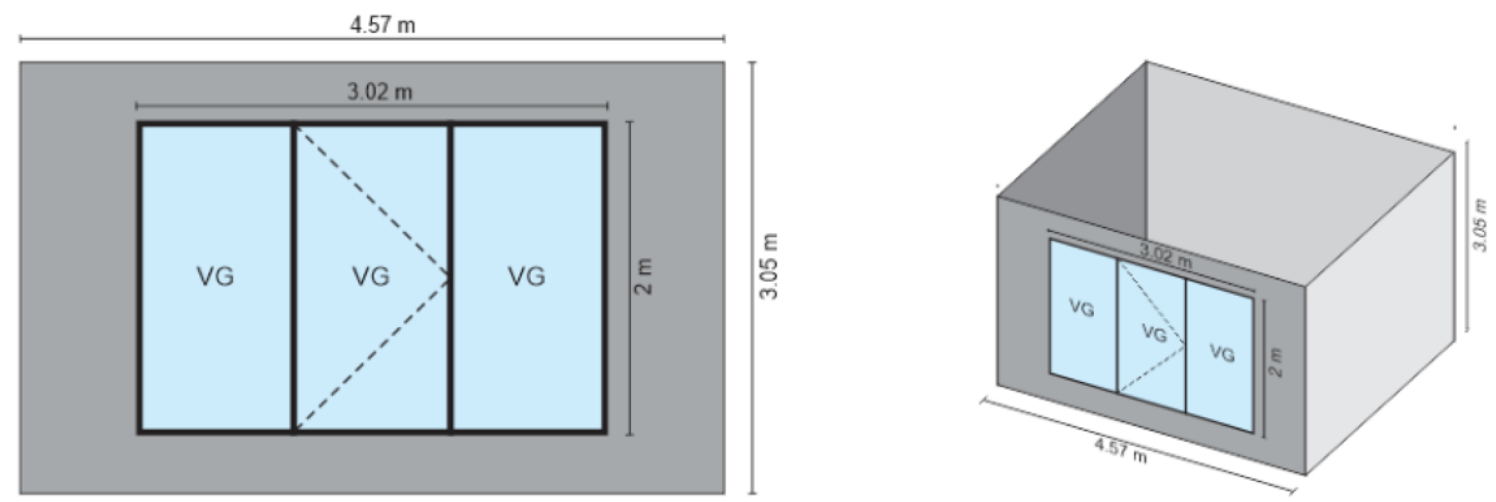

Figure 4.6: Operable Window: Overview of model (elevation and isometric view).
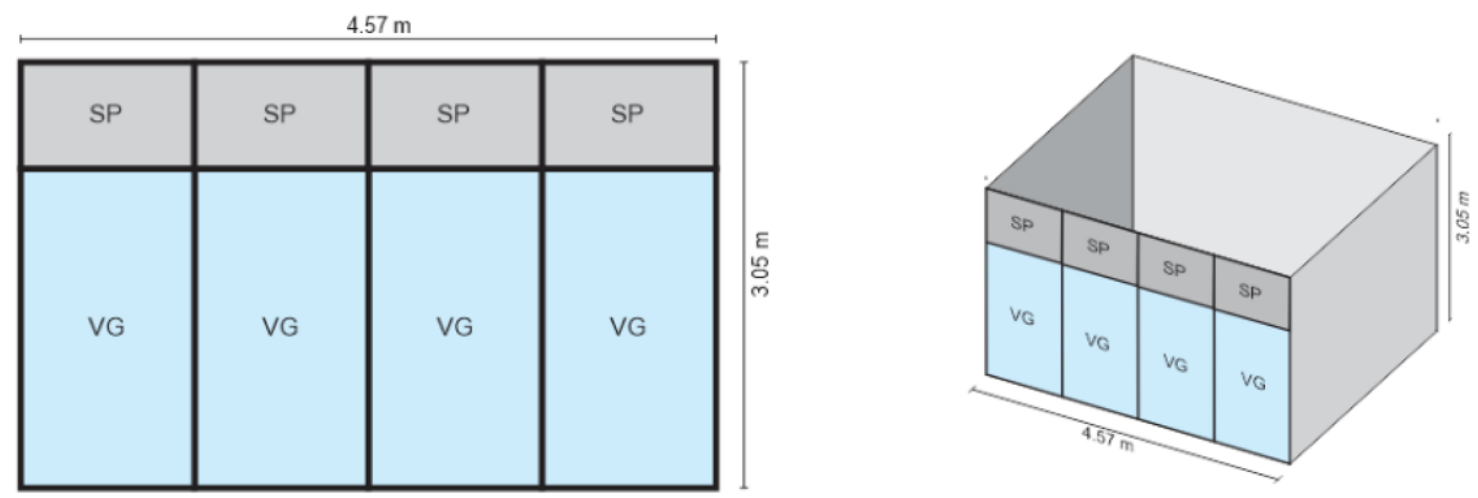

Figure 4.7: Curtain Wall: Overview of model (elevation and isometric view).

\subsubsection{Data imported and Calculation}

Calculated double clear air and SNG-SC coated glazing systems date were imported from the window program and data of Low-E argon glazing unit was selected from the COMFEN glazing library and applied to the proposed room and windows models.

Simulation engine ran for all scenarios (room and windows types) at each orientation (north, west, south and east) and location (section 4.1.7)

\subsubsection{Locations consider for this study}

Five cities in Canada (Toronto, Montreal, Halifax, Calgary and Vancouver) were considered for this study, to represent all climate zone in Canada. COMFEN library did not have climatic information of Halifax as default, so author imported climatic data of Halifax to COMFEN library from Energy Plus weather file and used for this study. 


\subsubsection{Display of Results}

Results were compared and analyzed for each scenario, façade orientation and location. Calculated annual energy savings, heating and cooling energy use, solar gain and other results were displayed in the graphical and tabular format.

\subsubsection{Simple Payback period calculation.}

COMFEN default engine was used for the simple payback time calculation. 


\section{RESULTS}

The annual energy performance of the SNG-SC coating has been calculated in COMFEN, for application with all window types (fixed, operable \& curtain wall) at each orientation in Toronto and compared with double clear air (base case scenario) and double low-E argon systems. The annual energy use intensity and saving results are presented in the following figures and tables.

\subsection{Experiment in Toronto}

\subsubsection{Fixed Window}

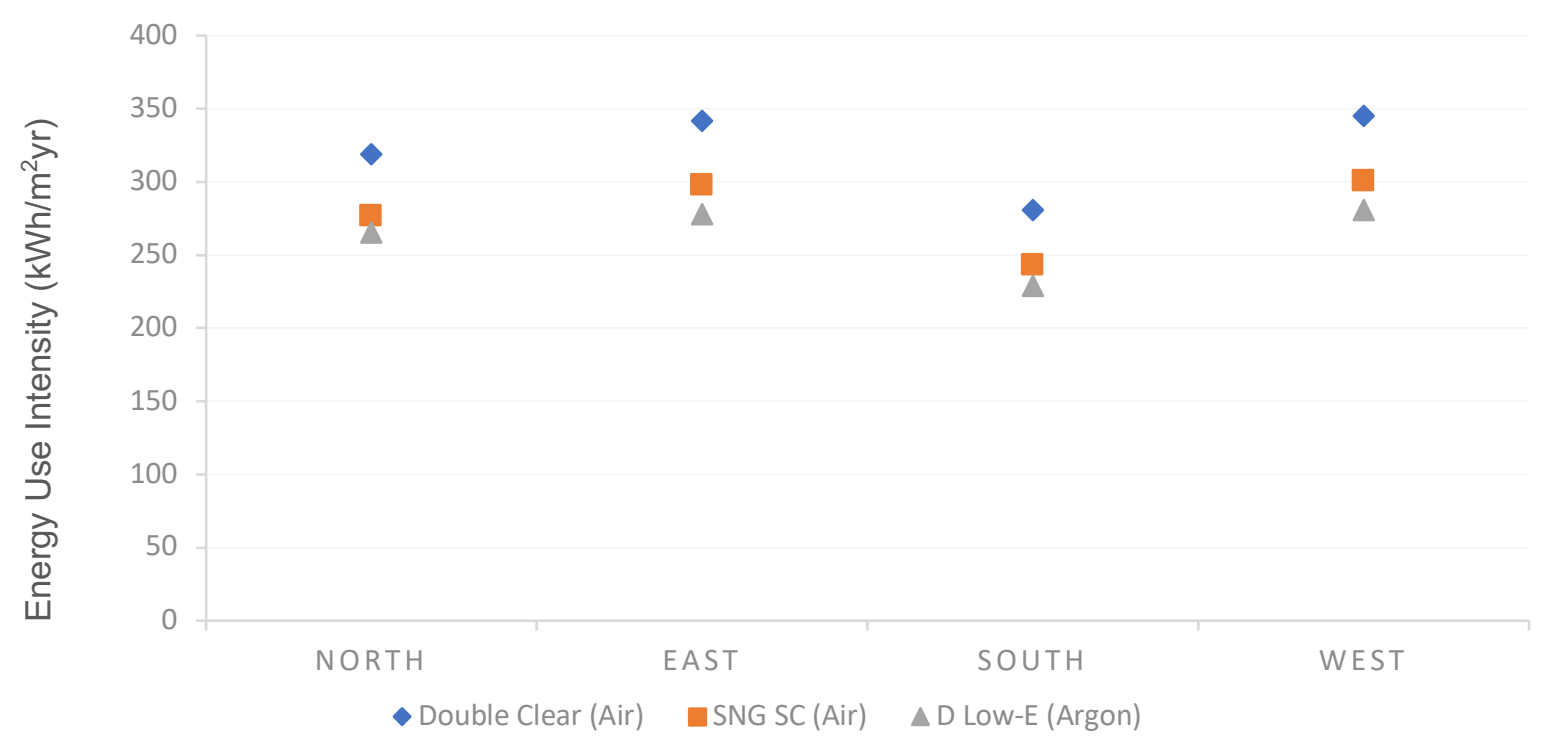

Figure 5.1: Energy use intensity for fixed window in Toronto.

\begin{tabular}{|l|l|l|l|l|l|}
\hline \multirow{2}{*}{ Orientations } & \multicolumn{3}{|l|}{ Energy Use Intensity=kWh/m²yr. } & \multicolumn{2}{l|}{ Annual Savings=\% } \\
\cline { 3 - 6 } & \multicolumn{3}{|l|}{$\begin{array}{l}\{\text { (DCA-SNG) } / \\
\text { DCA }\} * 100\end{array}$} & $\begin{array}{l}\{\text { (DCA-DLA)/ } \\
\text { DCA }\} * 100\end{array}$ \\
\cline { 2 - 6 } & $\begin{array}{l}\text { Double Clear } \\
\text { (Air) }\end{array}$ & $\begin{array}{l}\text { SNG-SC } \\
\text { (Air) }\end{array}$ & $\begin{array}{l}\text { D Low-E } \\
\text { (Argon) }\end{array}$ & SNG-SC (Air) & D Low-E (Argon) \\
\hline North & 319 & 277 & 266 & 13 & 17 \\
\hline East & 342 & 298 & 278 & 13 & 19 \\
\hline South & 281 & 243 & 229 & 13 & 18 \\
\hline West & 345 & 301 & 281 & 13 & 19 \\
\hline
\end{tabular}

*DCA=Double Clear Air, SNG-SC=Sketch NanoGard SC, DLA=Double Low-E Argon,

Table 5.1: Energy savings intensity for the fixed window in Toronto.

Application of the SNG-SC coating with the fixed window (window wall ratio; WWR 46\%) at different façade orientation in Toronto (figure $5.1 \&$ table 5.1) show coating performs well for 
every façade orientation. It saves $13 \%$ of total energy at each façade orientation compared to the base case scenario. The lowest energy demand for the base case scenario is $281 \mathrm{kWh} / \mathrm{m}^{2} \mathrm{yr}$ at the south orientation while application of the coating on the same façade orientation can lower the requirement to $243 \mathrm{kWh} / \mathrm{m}^{2} \mathrm{yr}$. Low-E glazing can further reduce its demand to $229 \mathrm{kWh} / \mathrm{m}^{2} \mathrm{yr}$ on the same orientation and saves 5\% more energy than SNG-SC coated glazing but need the replacement of window.

\subsubsection{Operable Window}

Application with the operable window (considering same WWR 46\%), SNG SC coating performs slightly better than the fixed window and saves $14 \%$ of total energy (figure $5.2 \&$ table 5.2). LowE glazing unit performs better at north and east façade and saves 3\% more energy than SNG SC coating and interesting to see SNC SC perform better (saves 14\%) than low-E unit (saves 11\%) at the west façade. One of the reasons for the better performance could be the SHGC of SNG SC coating is higher than Low-E glazing, may capture more free heat in winter from west side later part of the day.

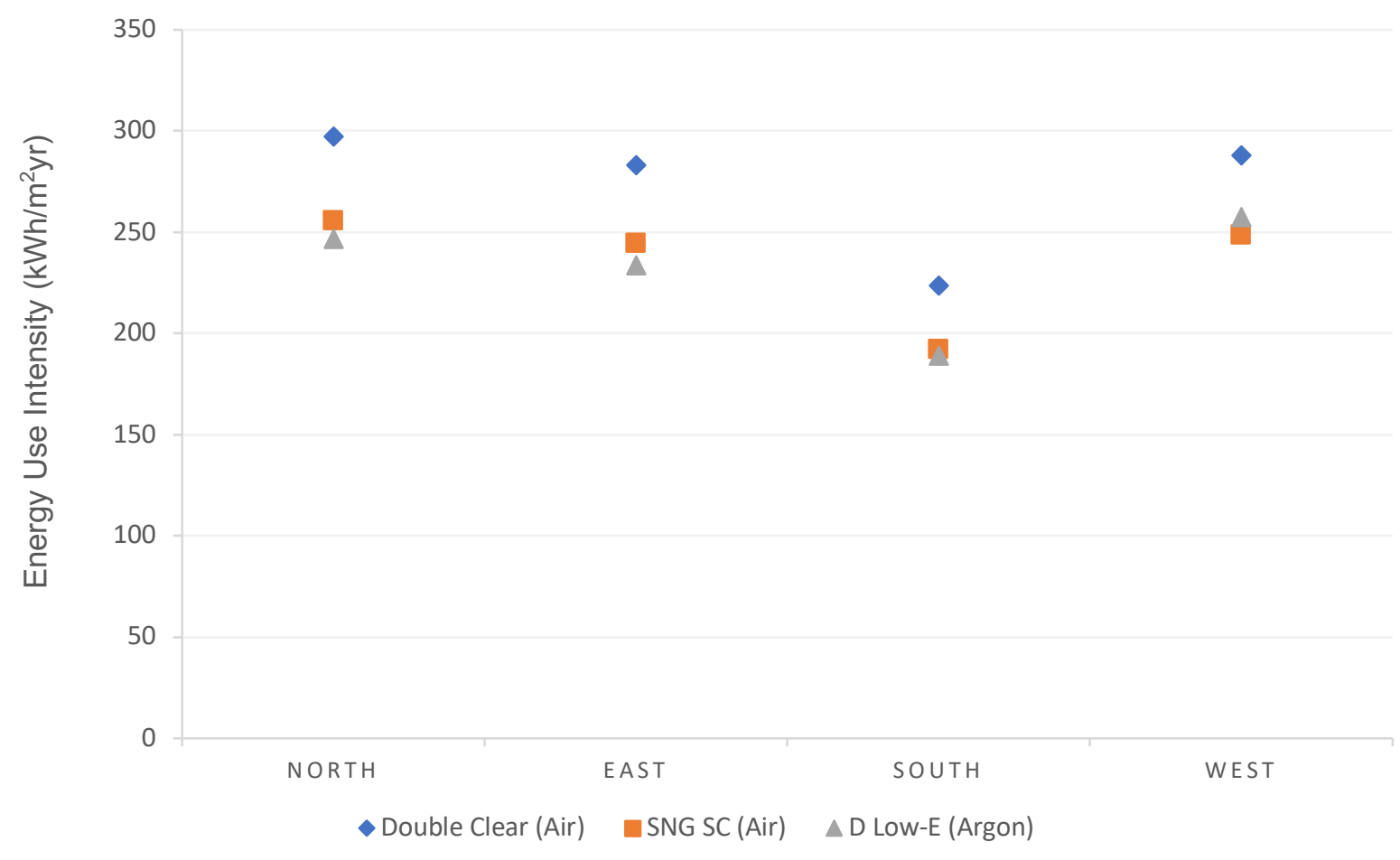

Figure 5.2: Energy use intensity for the operable window in Toronto. 


\begin{tabular}{|l|l|l|l|l|l|}
\hline Orientations & \multicolumn{3}{|l|}{ Energy Use Intensity=kWh/m²yr. } & \multicolumn{2}{l|}{ Annual Savings=\% } \\
\cline { 3 - 6 } & \multicolumn{3}{|l|}{$\begin{array}{l}\{\text { (DCA-SNG)/ } \\
\text { DCA }\} * 100\end{array}$} & $\begin{array}{l}\{\text { (DCA-DLA) } / \\
\text { DCA }\} * 100\end{array}$ \\
\cline { 2 - 6 } & $\begin{array}{l}\text { Double Clear } \\
\text { (Air) }\end{array}$ & $\begin{array}{l}\text { SNG-SC } \\
\text { (Air) }\end{array}$ & $\begin{array}{l}\text { D Low-E } \\
\text { (Argon) }\end{array}$ & SNG-SC (Air) & D Low-E (Argon) \\
\hline North & 298 & 256 & 247 & 14 & 17 \\
\hline East & 283 & 245 & 234 & 14 & 17 \\
\hline South & 224 & 192 & 189 & 14 & 16 \\
\hline West & 288 & 249 & 258 & 14 & 11 \\
\hline
\end{tabular}

Table 5.2: Energy savings intensity for operable window in Toronto.

\subsubsection{Curtain Wall}

Application with curtain wall (WWR 100\%), shows SNG-SC coating performs sound at the north façade and can save maximum 16\% of total energy (figure $5.3 \&$ table 5.3), though the difference with other directions is not very much significant (minimum $14 \%$ at east façade). Low-E coated glazing can save maximum $22 \%$ energy at the east, south and west orientations, that is $7 \%$ more energy saving than SNG-SC coated glazing.

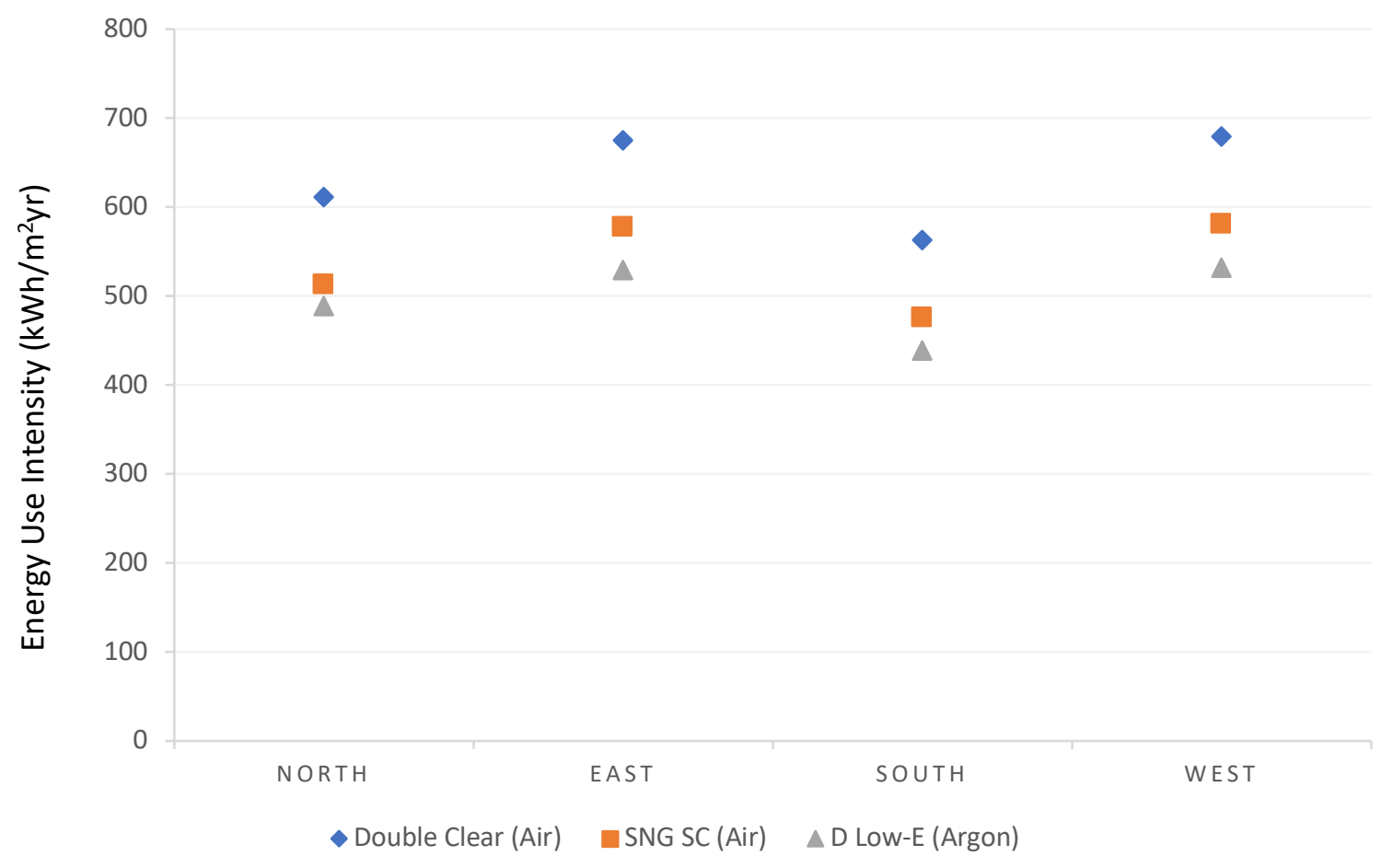

Figure 5.3: Energy use intensity for curtain wall in Toronto. 


\begin{tabular}{|c|c|c|c|c|c|}
\hline \multirow[t]{3}{*}{ Orientations } & \multirow{2}{*}{\multicolumn{3}{|c|}{ Energy Use Intensity $=\mathrm{kWh} / \mathrm{m}^{2} \mathrm{yr}$. }} & \multicolumn{2}{|c|}{ Annual Savings $=\%$} \\
\hline & & & & \multirow{2}{*}{$\begin{array}{l}\{(\mathrm{DCA}-\mathrm{SNG}) / \\
\mathrm{DCA}\} * 100 \\
\text { SNG -C (Air) }\end{array}$} & \multirow{2}{*}{$\begin{array}{l}\{\text { (DCA-DLA)/ } \\
\text { DCA }\} * 100 \\
\text { D Low-E (Argon) }\end{array}$} \\
\hline & $\begin{array}{l}\text { Double Clear } \\
\text { (Air) }\end{array}$ & $\begin{array}{l}\text { SNG-SC } \\
\text { (Air) }\end{array}$ & $\begin{array}{l}\text { D Low-E } \\
\text { (Argon) }\end{array}$ & & \\
\hline North & 611 & 513 & 488 & 16 & 20 \\
\hline East & 674 & 577 & 529 & 14 & 22 \\
\hline South & 563 & 476 & 439 & 15 & 22 \\
\hline West & 679 & 580 & 532 & 15 & 22 \\
\hline
\end{tabular}

Table 5.3: Energy savings intensity for curtain wall in Toronto.

The energy consumption and savings appear to be higher for coating, application with curtain wall and reasons could be higher window wall ratio (WWR). So, three fixed windows with different window wall ratios ( $\mathrm{WWR}=27 \% \& 46 \%$ and $\mathrm{WWR}=100 \%$ ) energy performance have been compared and analyzed for south orientation.

\subsection{Impact of wall ratio (WWR) on energy performance}

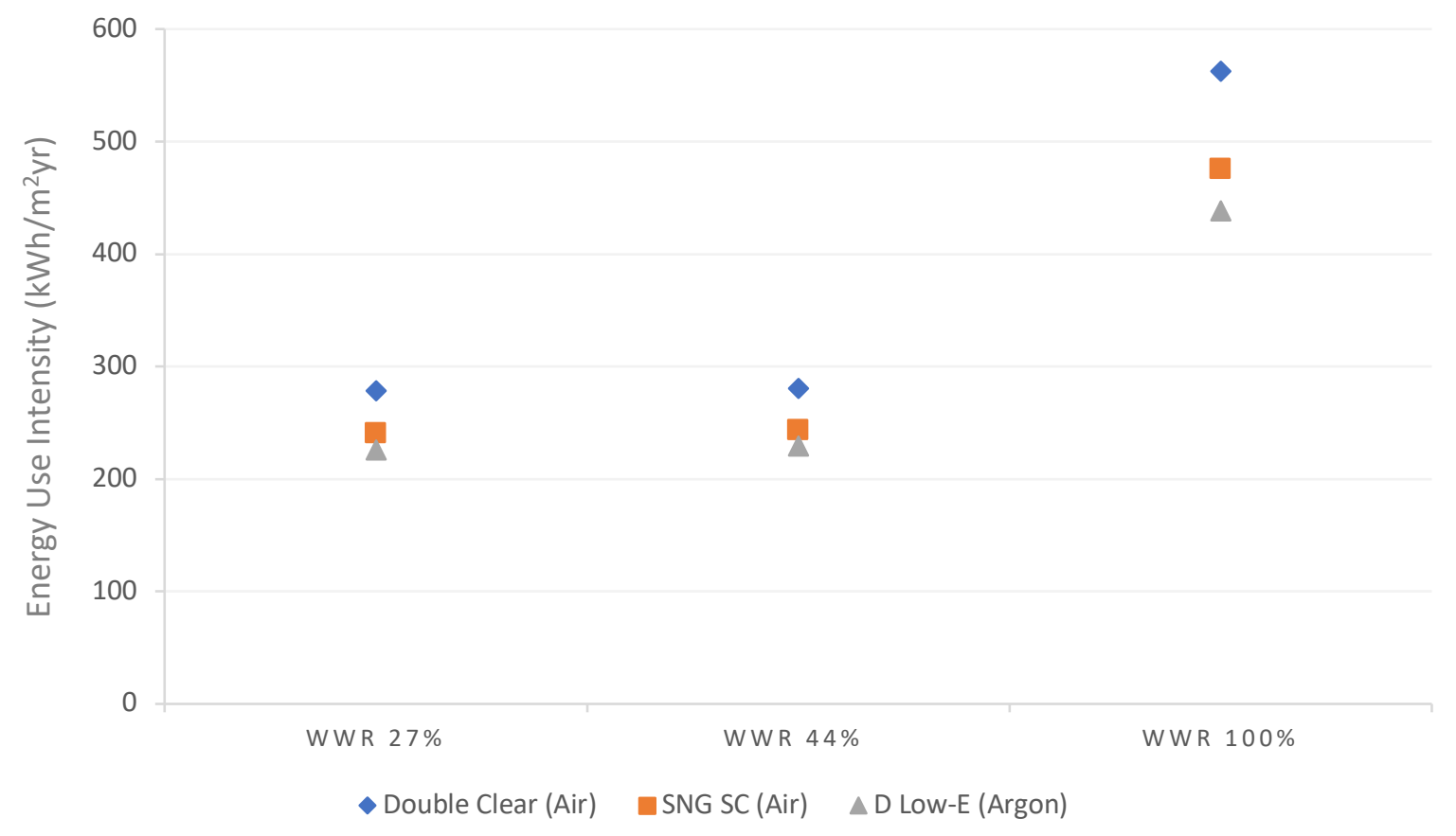

Figure 5.4: Impact of window wall ratio (WWR) on energy performance in Toronto.

Figure 5.4 shows that energy consumption increases steadily as the window wall ratio (WWR) increases. Energy consumption pattern of the proposed window model with WWR $=46 \%$ is slightly 
higher than the window model with WWR $=27 \%$ and demands remain between $200 \mathrm{kWh} / \mathrm{m}^{2} \mathrm{yr}$ and $300 \mathrm{kWh} / \mathrm{m}^{2} \mathrm{yr}$. When compared to the window model with WWR $=100 \%$, the energy demand went up to almost double to $500 \mathrm{kWh} / \mathrm{m}^{2} \mathrm{yr}$ as the WWR is increased to more than double.

\subsection{Heating and cooling energy demand for Toronto}

As the above study has shown, SNG-SC coating saved total energy for each scenario so, study tried to find out the heating and cooling energy consumption and savings behaviour for the fixed window in Toronto (figure 5.5 and table 5.4).

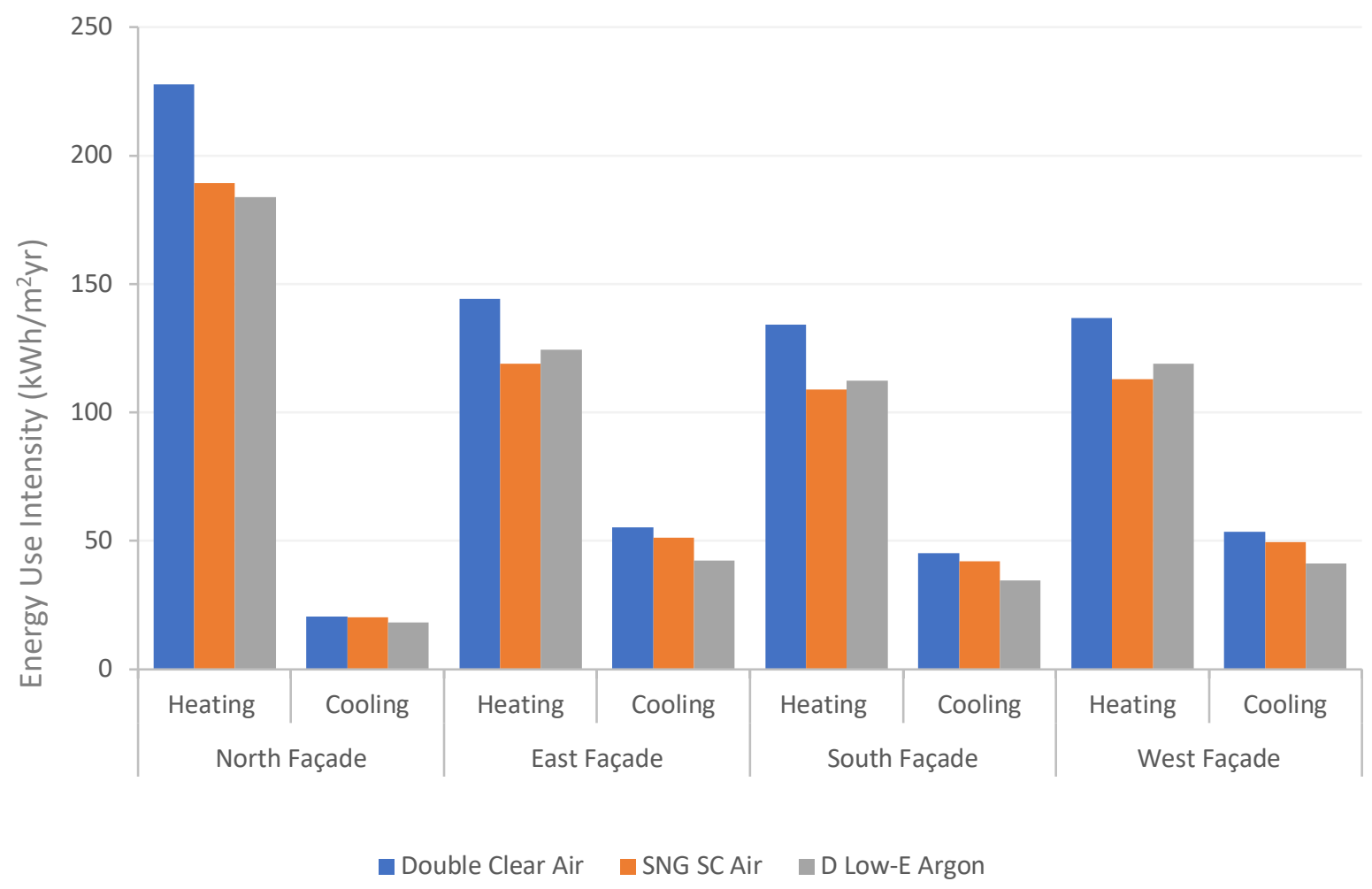

Figure 5.5: Heating and cooling energy savings pattern for the fixed window in Toronto.

Heating and cooling energy consumption and savings result shows, SNG-SC coating performs better on heating energy savings for the fixed window in Toronto and saves maximum 19\% of heating energy at the south façade (table 5.4). Performance on cooling energy savings are not very much significant, can save maximum $8 \%$ at east orientation and lowest performance recorded on the north facade, only $1 \%$. SNG-SC coating displays overall good performance on heating energy savings than double low-E glazing unit except at the north facade. Double Low-E glazing performs well on both heating and cooling energy savings. 


\begin{tabular}{|c|c|c|c|c|c|c|}
\hline \multirow[t]{3}{*}{ Orientations } & \multirow[t]{3}{*}{ Energy } & \multicolumn{3}{|c|}{ Energy use intensity $=\mathrm{kWh} / \mathrm{m}^{2} \mathrm{yr}$} & \multicolumn{2}{|c|}{ Annual Savings $=\%$} \\
\hline & & & & & \multirow{2}{*}{$\begin{array}{l}\{(\mathrm{DCA}-\mathrm{SNG}) / \\
\mathrm{DCA}\} * 100\end{array}$} & \multirow{2}{*}{$\begin{array}{l}\{(\mathrm{DCA}-\mathrm{DLA}) / \\
\mathrm{DCA}\} * 100 \\
\text { Double Low-E } \\
\text { Argon }\end{array}$} \\
\hline & & $\begin{array}{l}\text { Double } \\
\text { Clear Air }\end{array}$ & SNG-SC & $\begin{array}{l}\text { Double Low-E } \\
\text { Argon }\end{array}$ & & \\
\hline \multirow{2}{*}{$\begin{array}{l}\text { North } \\
\text { Facade }\end{array}$} & Heating & 228 & 189 & 184 & 17 & 19 \\
\hline & Cooling & 20 & 20 & 18 & 1 & 10 \\
\hline \multirow{2}{*}{$\begin{array}{l}\text { East } \\
\text { Facade }\end{array}$} & Heating & 144 & 119 & 124 & 18 & 14 \\
\hline & Cooling & 55 & 51 & 43 & 8 & 23 \\
\hline \multirow{2}{*}{$\begin{array}{l}\text { South } \\
\text { Facade }\end{array}$} & Heating & 134 & 109 & 112 & 19 & 16 \\
\hline & Cooling & 45 & 42 & 35 & 7 & 23 \\
\hline \multirow{2}{*}{$\begin{array}{l}\text { West } \\
\text { Facade }\end{array}$} & Heating & 137 & 113 & 119 & 18 & 13 \\
\hline & Cooling & 54 & 50 & 41 & 7 & 23 \\
\hline
\end{tabular}

Table 5.4: Heating and Cooling energy savings (\%) for the fixed window in Toronto.

\subsection{Other Cities}

Montreal, Halifax, Calgary and Vancouver have also been considered for this study to look at the SNG-SC coating energy savings performance at other locations in Canada.

\subsubsection{Fixed Window}

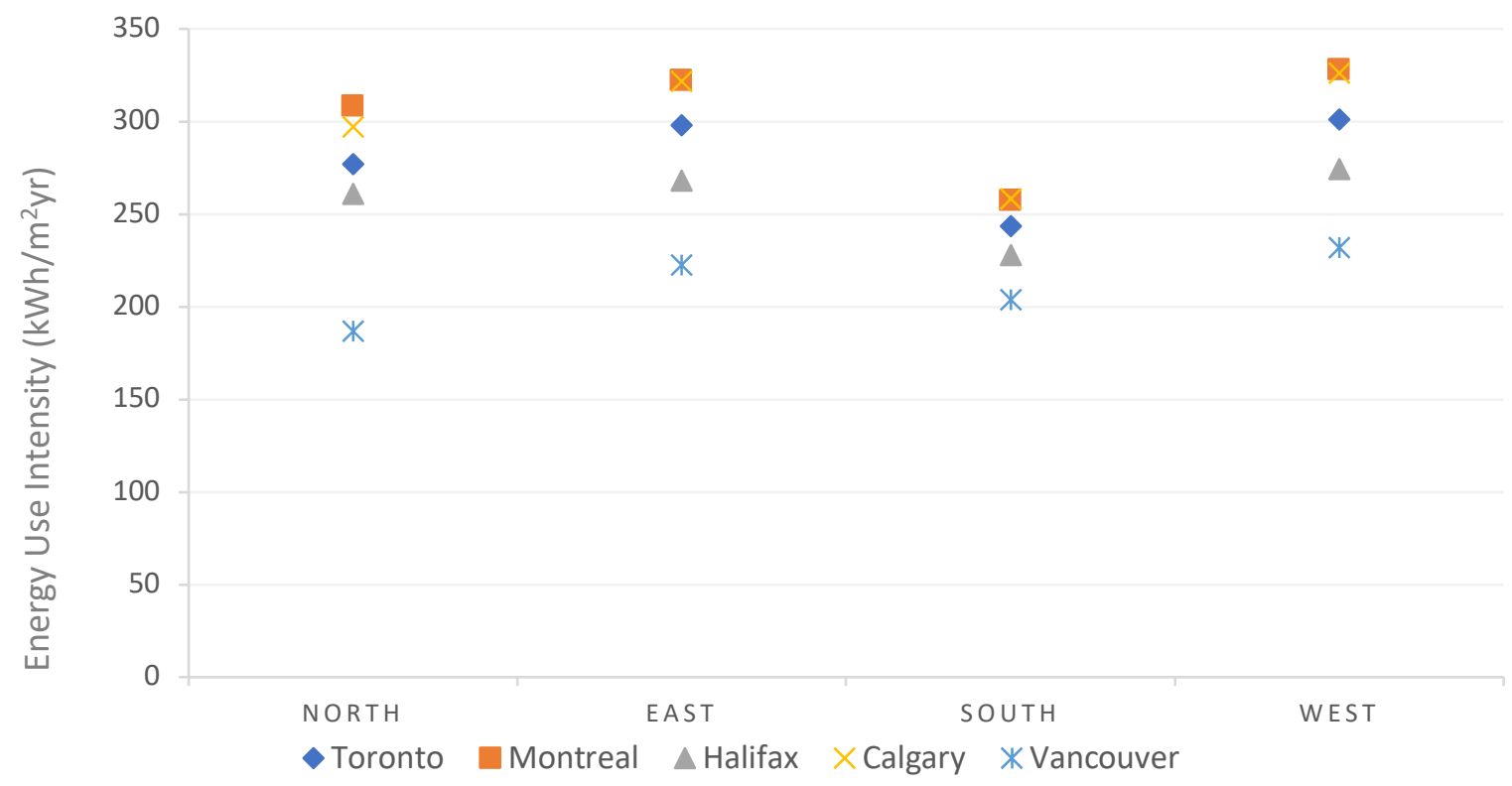

Figure 5.6: Energy consumption for the fixed window among cities.

Figure 5.6 shows the energy consumption pattern of the SNG-SC coating when applied at each climatic location and orientation. Table 5.5 shows the annual energy savings performance compared to the base case scenario for the particular area. 


\begin{tabular}{|l|l|l|l|l|l|}
\hline \multirow{5}{*}{ Orientations } & \multicolumn{5}{|l|}{ Annual Energy Savings (\%) of SNG SC at different Cities in Canada } \\
\cline { 2 - 6 } & $\begin{array}{l}\{\text { (DCA-SNG) } / \\
\text { DCA }\} * 100\end{array}$ & $\begin{array}{l}\{\text { (DCA-SNG) } / \\
\text { DCA }\} * 100\end{array}$ & $\begin{array}{l}\{\text { (DCA-SNG) } / \\
\text { DCA }\} * 100\end{array}$ & $\begin{array}{l}\{\text { (DCA-SNG)/ } \\
\text { DCA }\} * 100\end{array}$ & $\begin{array}{l}\{\text { (DCA-SNG) } / \\
\text { DCA }\} * 100\end{array}$ \\
\cline { 2 - 6 } & Toronto & Montreal & Halifax & Calgary & Vancouver \\
\hline North & 13 & 13 & 14 & 14 & 15 \\
\hline East & 13 & 12 & 13 & 13 & 13 \\
\hline South & 13 & 13 & 13 & 13 & 12 \\
\hline West & 13 & 12 & 13 & 13 \\
\hline
\end{tabular}

Table 5.5: Energy savings (\%) compared among cities (fixed window).

Vancouver shows the best energy saving performance especially at the north orientation and saves a maximum $15 \%$ of total energy. Second best performance recorded in Halifax and Calgary and save $14 \%$ each at north orientation. Lowest performance noted in Montreal 12\% at west orientation, but the total energy savings differences among cities and orientations $(2 \%)$ are not very much significant.

\subsubsection{Operable Window}

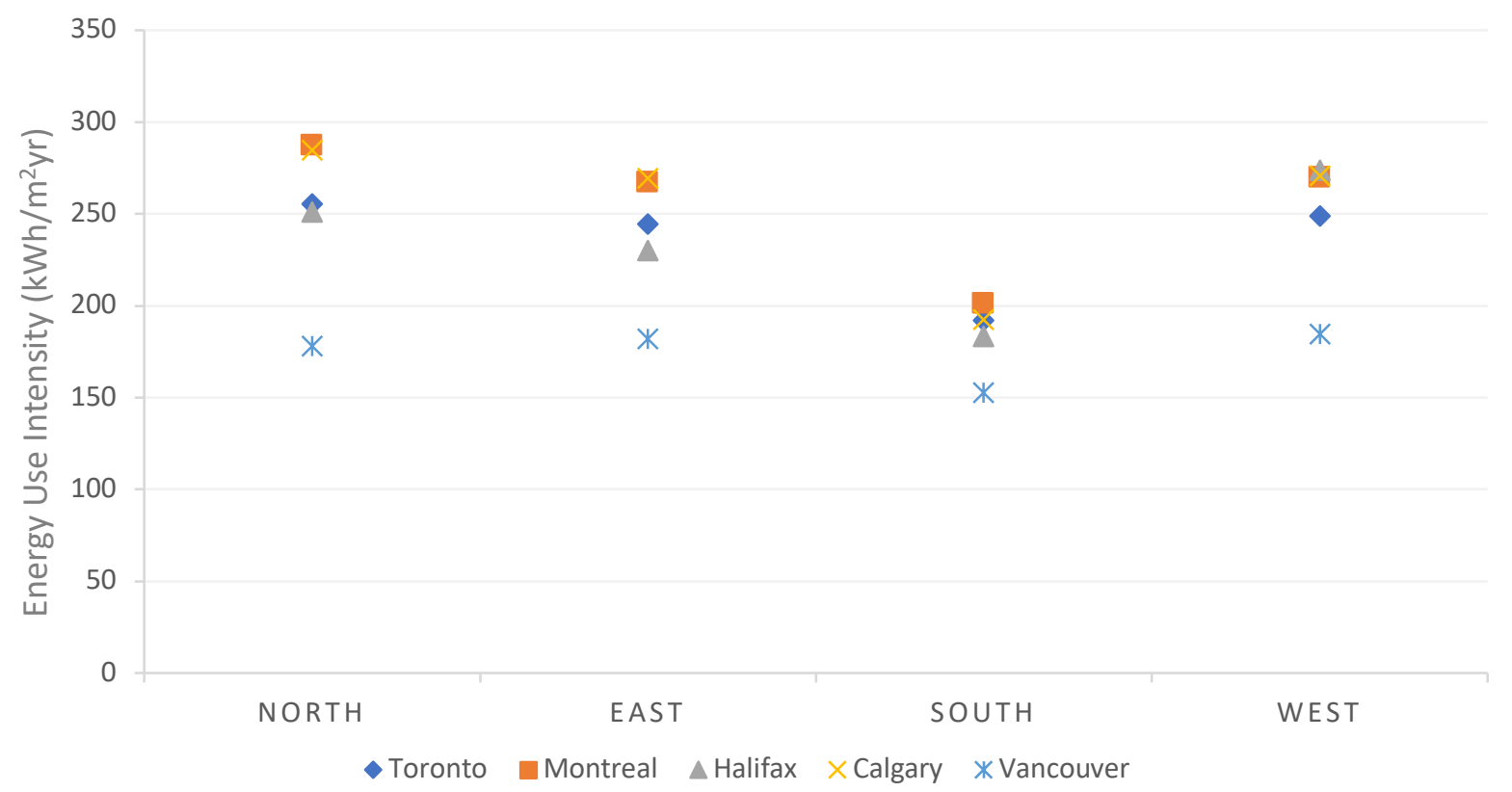

Figure 5.7: Energy consumption (operable window) compared among cities

Result in table 5.6 shows, SNG-SC coating application with operable window performs slightly better than fixed window too among cities. Vancouver also shows overall best energy performance at the north façade and saves $16 \%$ of total energy. Toronto shows overall second-best performance. 


\begin{tabular}{|l|l|l|l|l|l|}
\hline \multirow{5}{*}{ Orientations } & \multicolumn{5}{|l|}{ Annual Energy Savings (\%) of SNG SC at different Cities in Canada } \\
\cline { 2 - 7 } & $\{$ (DCA-SNG) $/$ & $\begin{array}{l}\{\text { (DCA-SNG) } / \\
\text { DCA }\} * 100\end{array}$ & $\begin{array}{l}\{\text { (DCA-SNG) } / \\
\text { DCA }\} * 100\end{array}$ & $\begin{array}{l}\{\text { (DCA-SNG)/ } \\
\text { DCA }\} * 100\end{array}$ & $\begin{array}{l}\{\text { (DCA-SNG) } / \\
\text { DCA }\} * 100\end{array}$ \\
\cline { 2 - 7 } & DCA $\} * 100$ & Montreal & Halifax & Calgary & Vancouver \\
\hline North & 14 & 13 & 14 & 14 & 16 \\
\hline East & 14 & 13 & 14 & 13 & 14 \\
\hline South & 14 & 13 & 14 & 13 & 14 \\
\hline West & 14 & 13 & 13 & 13 & 14 \\
\hline
\end{tabular}

Table 5.6: Energy savings (\%) compared among cities (operable window).

\subsection{Heating and Cooling energy analysis among cities}

Heating and cooling energy demand and savings results have also been compared and analyzed for the fixed window among cities and presented in the figure and table below.

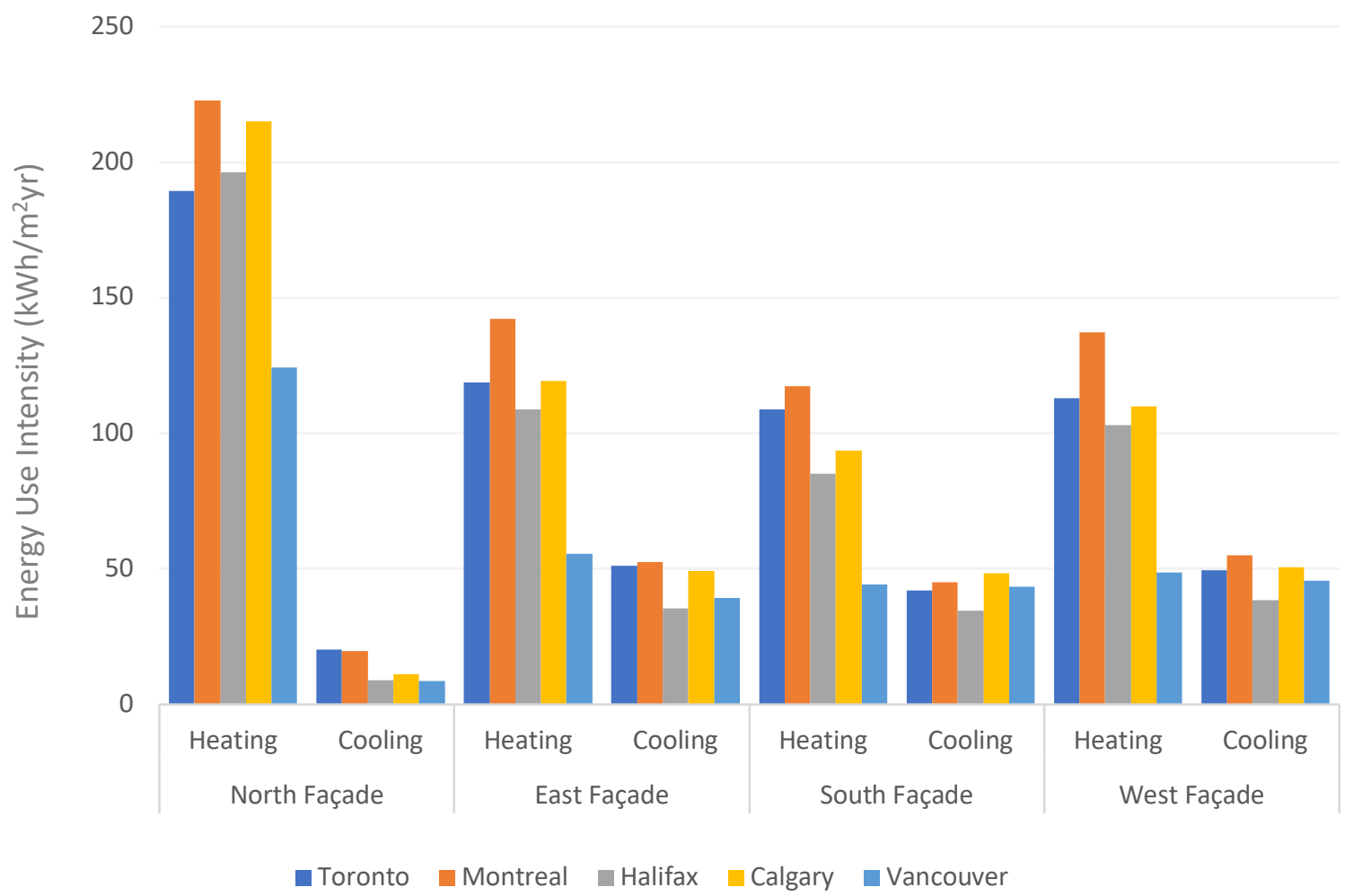

Figure 5.8: Heating energy consumption (fixed window) among cities.

Figure 5.7 and table 5.7 show, SNG-SC coating, performs good and saves a significant amount of heating energy at each location considered for this study. Maximum 27\% savings recorded in Vancouver at the south orientation. Application in Halifax also shows good performance and saves $20 \%$ at the same orientation. 


\begin{tabular}{|l|l|l|l|l|l|}
\hline \multirow{5}{*}{ Orientations } & \multicolumn{5}{l}{ Heating Energy Savings (\%) of SNG SC at different Cities in Canada } \\
\cline { 2 - 7 } & $\{$ (DCA-SNG)/ & $\begin{array}{l}\{\text { (DCA-SNG) } / \\
\text { DCA }\} * 100\end{array}$ & $\begin{array}{l}\{\text { (DCA-SNG) } / \\
\text { DCA }\} * 100\end{array}$ & $\begin{array}{l}\{\text { (DCA-SNG)/ } \\
\text { DCA }\} * 100\end{array}$ & $\begin{array}{l}\{\text { (DCA-SNG) } / \\
\text { DCA }\} * 100\end{array}$ \\
\cline { 2 - 7 } & TCA $\} * 100$ & Montreal & Halifax & Calgary & Vancouver \\
\hline North & 17 & 16 & 17 & 17 & 21 \\
\hline East & 18 & 16 & 18 & 17 & 24 \\
\hline South & 19 & 17 & 20 & 19 & 27 \\
\hline West & 18 & 16 & 18 & 17 & 25 \\
\hline
\end{tabular}

Table 5.7: SNG-SC coating heating energy savings \% among cities.

Table 5.8 shows SNG-SC Coating does not perform well for cooling energy savings and maximum 9\% energy savings recorded at the south orientation in Calgary. Application with north façade among cities show its poorest performance to cooling energy. Toronto and Montreal save only $1 \%$ at the north orientation, but other places like; Halifax, Calgary and Vancouver demand more cooling energy instead of savings.

\begin{tabular}{|c|c|c|c|c|c|}
\hline \multirow[t]{3}{*}{ Orientations } & \multicolumn{5}{|c|}{ Cooling Energy Savings (\%) of SNG SC at different Cities in Canada } \\
\hline & $\begin{array}{l}\{(\mathrm{DCA}-\mathrm{SNG}) / \\
\mathrm{DCA}\} * 100\end{array}$ & $\begin{array}{l}\{(\mathrm{DCA}-\mathrm{SNG}) / \\
\mathrm{DCA}\} * 100\end{array}$ & $\begin{array}{l}\{(\mathrm{DCA}-\mathrm{SNG}) / \\
\mathrm{DCA}\} * 100\end{array}$ & $\begin{array}{l}\{(\mathrm{DCA}-\mathrm{SNG}) / \\
\mathrm{DCA}\} * 100\end{array}$ & $\begin{array}{l}\{(\mathrm{DCA}-\mathrm{SNG}) / \\
\mathrm{DCA}\} * 100\end{array}$ \\
\hline & Toronto & Montreal & Halifax & Calgary & Vancouver \\
\hline North & 1 & 1 & 6* & $5 *$ & $10 *$ \\
\hline East & 8 & 8 & 6 & 8 & 6 \\
\hline South & 7 & 7 & 7 & 9 & 7 \\
\hline West & 7 & 8 & 7 & 8 & 7 \\
\hline
\end{tabular}

* Note: Demand more cooling energy consumption instead of savings.

Table 5.8: SNG-SC coating cooling energy savings \% compared among cities.

\subsubsection{Cooling Energy Demand among three cities}

As the application of SNG-SC coating with the fixed window at some locations demand more cooling energy instead of savings so, coating's cooling energy demand has been compared (figure 5.9) and analyzed again with base case scenario and double low-E glazing unit. 


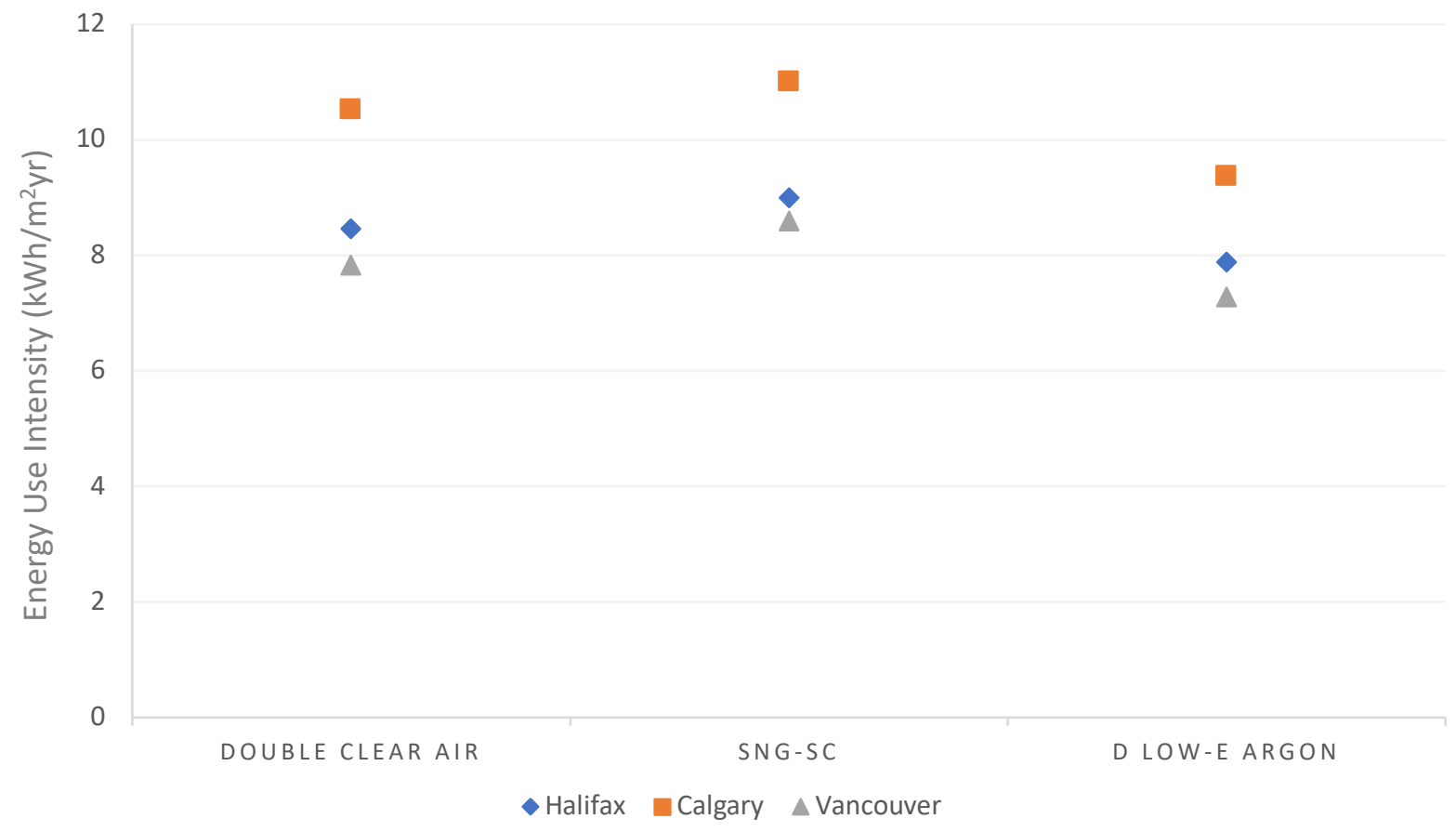

Figure 5.9: Cooling energy consumption pattern among cities for the fixed window.

The result in figure 5.9 shows, cooling energy demand increases steadily from the base case scenario to SNG-SC coating and again decrease to the Low-E glazing. It could be due to the warm summer and coating's SHGC is higher than base case scenario. It can capture more solar energy and due to the fixed window, more energy needed for cooling.

\subsection{Simple payback analysis}

The payback period disregards the time value of money (TVM), unlike other methods of capital budgeting such as net present value (NPV), internal rate of return (IRR) and discounted cash flow. The payback calculation in COMFEN only takes into consideration the annual energy savings of the scenarios, window wall ratio and climatic condition. For each option, the following initial costs were collected from the manufacturer, service provider and users and replaced with default COMFEN electricity and gas cost.

- SNG-SC coating application $=\$ 129 / \mathrm{m}^{2}$

- Double Low-E argon glazing replacement $=\$ 516 / \mathrm{m}^{2}$

- Electricity $=\$ 0.29 / \mathrm{kWh}$ and Natural gas $=\$ 0.16 / \mathrm{m}^{3}$ 
The energy cost savings per square meter was calculate based on the $13.94 \mathrm{~m}^{2}$ room area in the modled perimeter zone. The cost of the coating per square meter estimated based on the window area modeled in the same zone with 0.46 window wall ratio. The coating on glazing for windows retrofit provide opportunities for the fastest payback, are in the ranges of 4 to 5.5 years (figure 5.10) while for the windows replacement with low-E argon unit required between 12 and 17 years to recover the initial project cost. Quickest payback time observed in Calgary because it saves the highest amount of energy $134 \mathrm{kWh} / \mathrm{m}^{2} \mathrm{yr}$ among studied locations. This model-based payback calculations in COMFEN program is provided primarily for rough guidance and relative comparisons. Any individual project should be evaluated based on the particular climate and building characteristics including windows area (window-to-wall ratio), orientation, shading, base window configuration, etc. An implicit assumption, in the use of payback period is that returns to the investment continue after the payback period.

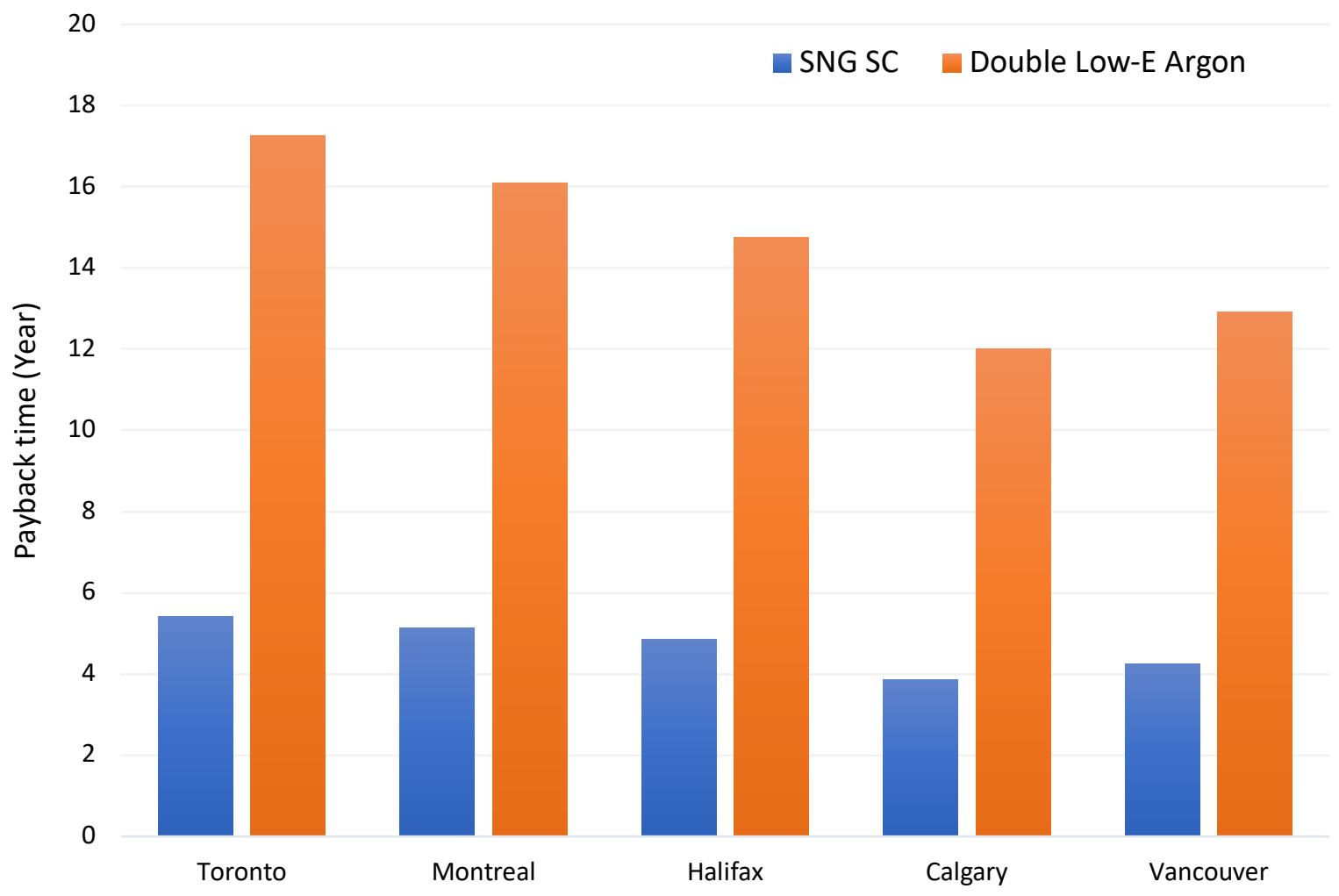

Figure 5.10: Simple payback time graph among cities between retrofit and replacement. 


\section{CONCLUSIONS}

The improved spectral values obtained with SNG-SC coating were studied from the technical data sheet and sample glass test data. The calculated results from LBNL Optics and Window program have shown that It allows solar energy to pass through coated glazing while it can block the harmful ultraviolet (UV) rays and infrared (IR) rays. The results from COMFEN simulation study have been analyzed for total energy savings and annual heating and cooling energy performance for the proposed options at each location and orientation. Annual energy savings of the coating for windows retrofit were observed in the range of $13 \%$ to $16 \%$, while for the windows replaced with low-e argon glazing unit saved between $11 \%$ and $22 \%$. The coating also saved substantial heating energy for each location ( $17 \%$ to $25 \%$ ), but the cooling energy saving performance is not very much significant (1\% to 9\%). Besides, some locations; Halifax, Calgary and Vancouver demand more cooling energy instead of savings, whereas manufacturers data shows the coating reduces heat penetration through windows, decreasing air conditioning needs in the summer. It is to be noted that the calculation methods of this study may be different than manufactures test methods. Modeled savings were not directly comparable to the actual savings as sufficient data from the manufacturer were not available. The application of SNG-SC coating is very much useful in total energy use reduction for existing low-performance windows in the Canadian climate. Results also show that the coating performs slightly better with an operable window than the fixed window. Though the coating does not perform very well compare to low-e argon glazing unit (for the window replacement), coating is one of the most cost-effective energy savings options to achieve the high energy performance of the existing windows. This coating is especially beneficial in Canadian climates as it significantly reduces heat loss from home in the winter time. The most important thing is, the coating is comparatively cheap, easy to install and offer the fastest payback. The application can be performed quickly with minimum disruption to the building occupants. The other factors may enter into the evaluation of the annual energy savings for specific cases, such as historic buildings that require expensive maintenance. A historic building may more easily maintain the original look of the glass with a coating like the one studied in this work. The coating can improve thermal performance and lower the electricity bill. 


\section{REFERENCES}

AAAMSA, (2012). Association of architectural aluminum manufacturers of South Africa. Chapter IV. Selection of Glazing Materials. August 2012.

https://www.aaamsa.co.za/docs_new/AAAMSA/AAAMSA_Selection_Guide_Chapter_4_Glazin g_Materials.pdf

Alumicor, (2011). Alumicor Limited. Thermal wall 2600 thermal wall simulation chart. Thermal simulation chart guide. https://www.alumicor.com/documents/p1_3_5_2 4\%20ThermaWall\%202600\%20Thermal\%20Charts.pdf

Apte, J. and Arasteh, D., (2006). Window-Related Energy Consumption in the US Residential and Commercial Building Stock. Berkeley, CA, Lawrence Berkeley National Laboratory: LBNL60146.

Armstrong, M.M., Swinton, M.C., Elmahdy, A.H., \& Parekh, A., (2008). Selecting Residential Window Glazing for Optimum Energy Performance. National Research Council of Canada September 2008. ISSN 1206-1220

https://www.nrc-cnrc.gc.ca/ctu-sc/wp-content/uploads/sites/5/2008/ctu71/doc/ctu-n71_eng.pdf

Berardi, U., (2017). Report 1.2: Sketchnanogard-SC thermal coating for windows for sketch nanotechnologies Inc., Ryerson University, Toronto, ON.

CG, (2018). Convenience group. 3M architectural and window film solutions. Increase Your Home's Energy Efficiency. http://www.conveniencegroup.com/residential-energy-efficiency

Curcija, C., Goudey, H. and Mitchel, R., (2017). Low-e Applied Film Window Retrofit for Insulation and Solar Control. February 2017. Lawrence Berkeley National Laboratory (LBNL). Office of the Commissioner, Public Buildings Service U.S. General Services Administration, 50 United Nations Plaza, Room 3667, San Francisco, CA 94102-4912.

CMHC, (2012). Canada Mortgage and Housing Corporation. Energy Efficiency Building Envelope Retrofits fact sheets. Energy Efficiency Building Envelope Retrofits for Your House.

City Green, (2004). Consumer's Guide to Buying Energy-Efficient Windows and Doors. https://www.citygreen.ca/cgFiles/windows-doors.pdf

CW, (2018). Commercial Window. Windows for high performance commercial buildings. Window Technologies. Properties Primer. Transmittance.

https://www.commercialwindows.org/transmittance.php

Ecoline, (2018). Ecoline windows. 5 Benefits of Triple Pane Glass for Window Replacement. https://www.ecolinewindows.ca/5-benefits-of-triple-pane-glass-for-window-replacement/ 
GG, (2018). Guardian Glass. Tools and resources for research and specification writing.

Glazing and wet glazing.

https://www.guardianglass.com/commercial/ToolsandResources/Resources/GlossaryandTerms/

WetGlazing/index.htm

Hanam, B., Finch, G., and Ricketts, D., (2012). Thermal importance of window. Construation

Canada. April 1, 2012. https://www.constructioncanada.net/thermal-importance-of-windows/

Hydro Quebec, 2018. Electricity rates and Conditions of service.

http://www.hydroquebec.com/documents-data/official-publications/electricity-rates-conditionselectricity-service.html

IGDB, 2018. The International Glazing Database. How to Provide Data to the IGDB. Overview of Requirements for the IGDB. The Lawrence Berkeley National Laboratory (LBNL). https://windows.lbl.gov/submitting-data

Lee, S.K., Chen, H.J., Fan, K., Hsi, H., Horng, R.S, (2014). Thermal performance and durability properties of the window glazing with exterior film (s). Indoor and Built Environment, 2014, Vol. 23(8) 1163-1176. The Author(s) 2013. sagepub.co.uk/

Li, C., Tan, J., Chow, J.T. and Qiu, Z., (2015). Experimental and theoretical study on the effect of window films on building energy consumption. Energy and Buildings 102 (2015)129-138. Science Direct. 0378-7788/C 2015 Elsevier B.V. All rights reserved.

Mainini, A. G., Bonato, D., Poli, T. and Speroni, A., (2015). Lean strategies for window retrofit of Italian office buildings: impact on energy use, thermal and visual comfort. Energy Procedia 70 (2015) 719-728. ScienceDirect. 1876-6102 (C) 2015 The Authors. Published by Elsevier Ltd.

Mitchell, R., Yazdanian, M., Zelany, Z. and Curcija, C., (2012). For Calculating the Energy Demand and Comfort Impacts of Windows in Commercial Buildings. Windows and Daylighting Group, Building Technologies Program, Environmental Energy Technologies Department, Lawrence Berkeley National Laboratory, Berkeley, CA 94720, USA.

https://windows.lbl.gov/comfen-documentation

Mohelnikova, M., (2009). Infrared Reflective Coatings for Window Glazing. Solid State Phenomena Vol. 144 (2009) pp 226-231. Online available since 2008/Sep/26 at www.scientific.net (C) (2009) Trans Tech Publications, Switzerland.

Moretti, E. and Belloni, E., (2015). Evaluation of energy, thermal, and daylighting performance of solar control films for a case study in moderate climate. Building and Environment 94 (2015) 183e195. (C) 2015 Elsevier Ltd. All rights reserved.

NMHydro, (2018). Conserve. Energy loss through windows and doors http://www.nmhydro.ca/pdf/tips/Energy\%20loss\%20through\%20windows\%20and\%20doors.pdf 
NREL, (2014). National Renewable Energy Limited. Continuum. Clean energy innovation at NREL. energy saving homes \& buildings. Spring 2014/issues 6.

NRCan, (2003). Consumer's Guide to Buying Energy-Efficient Windows and Doors. http://publications.gc.ca/site/archiveearchived.html?url=http://publications.gc.ca/collections/Collection/M92-156-2003E.pdf NRCan, (2011). Natural Resources Canada. Eco Energy, an Eco action initiative. EnergyEfficient Residential Windows, Doors and Skylights, Updated October 2010.

NRCan, (2014). Natural Resources Canada. Major Energy Retrofit Guidelines for Commercial and Institutional Buildings. Office buildings. Cat. No. M144-275/3-2016E-PDF, ISSN 978-0660-06728-5.

NREL, (2014). National Renewable Energy Limited. Continuum. Clean energy innovation at NREL. energy saving homes \& buildings. Spring 2014/issues 6.

NRCan, (2017). Major Energy Retrofit Guidelines for Commercial and Institutional Buildings.http://www.nrcan.gc.ca/sites/www.nrcan.gc.ca/files/oee/buildings/pdf/NRCan_Retrofit NF_Retail_en.pdf

NRCan, (2017). Fenestration (windows and doors) http://www.nrcan.gc.ca/energy/products/categories/fenestration/13739

NRCan, (2017). Keeping the Heat In - Chapter 8: Upgrading windows and doors http://www.nrcan.gc.ca/energy/efficiency/housing/home-improvements/keeping-the-heatin/upgrading-windows-and-doors/15643\#a8-1

NRCan. (2018). Fenestration (windows and doors). Buy ENERGY STAR ${ }^{\circledR}$ certified windows, doors and skylights (Fenestration products) to save you money! https://www.nrcan.gc.ca/energy/products/categories/fenestration/13739

NRCan, (2018). Natural Resource Canada. Windows, doors and skylights - ENERGY STAR Canada technical specification. Defination. Product type. Windows.

Optics, (2018). The tool for manipulating optical layers and calculating spectral data for different stacks of optical elements. The Lawrence Berkeley National Laboratory (LBNL). https://windows.lbl.gov/tools/optics/knowledge-base

Okanaganway, (2018). Manufactured windows, doors and skylights for part 9 buildings. Fenestration requirements and guidelines (NAFS). District of Lake Country. https://lakecountry.civicweb.net/document/62481

Padiyath, R. and Seth, J., (2007). 3M Company. Energy efficient IGUs with polymeric near infrared reflecting films. Glass performance days, Finland, 2007. www.gpd.fi. http://glassfiles.cc.tut.fi/articles/energy-efficient-igus-polymeric-near-infrared-reflecting-films 
Peng,J., Goudey, H., Thanachareonkit, A., Curcija,C. and Lee, E.,( 2017).

Measurement \& Verification of the performance of solaria BIPV in FLEXLAB Test facility.

Energy Technologies Area. Lawrence Berkeley National Laboratory.

RDH, (2017). Windows Energy Performance. A Reference Guide for Energy Advisors. Prepared by RDH building science Inc for FortisBC and BC Hydro. February 2017.

http://www.citygreen.ca/cgFiles/RDH-Reference-Guide-for-Energy-Advisors.pdf

Schroeder, D., (2018). Update or Replace Windows. US Department of Energy. https://www.energy.gov/energysaver/design/windows-doors-and-skylights/update-or-replacewindows

Selkowitz, S., (2011). Stephen Selkowitz. Windows and Daylighting Group Building Technologies Department. Lawrence Berkeley National Laboratory (LBNL). IEA Building Envelope Technologies and Policies Workshop, Paris, 17/11/2011

Sketchnano, (2018). Sketch nanotechnologies. Why is a Thermal Coating a Better Option Than Window Films and Tints? https://www.sketchnano.com/articles/thermal-coating-better-option-window-films-tints/

Smith, N., Isaacs, N., Burgess, J. and Cox-Smith, I., (2012). Thermal performance of secondary glazing as a retrofit alternative for single-glazed windows. Energy and Buildings 54 (2012) 4751. (C) 2012 Elsevier B.V. All rights reserved.

Spurce, (2018). The Spurce. How Retrofit Windows Can Save the High Cost of Replacement. https://www.thespruce.com/retrofit-windows-can-save-money-1822932

TW, (2018). Trend Windows and doors. Energy efficiency. Solar Heat gain Coefficient (SHGC). http://www.trendwindows.com.au/information/energy-efficiency/solar-heat-gain-co-efficientshgc/

U.S. Energy Information Administration (2012). Annual Energy Outlook 2012- with Projections to 2035. DOE/EIA-0383(2012).

US Department of Energy, (2010). Buildings Energy Data Book. Energy Efficiency and Renewable Energy. Tables 1.1.1 and 1.2.3.

US Department of Energy, (2018). Update or Replace Window. https://www.energy.gov/energysaver/design/windows-doors-and-skylights/update-or-replacewindows

Vitro, (2018). Vitro Architectural Glass. What is Low-e Glass. Low-e Coating Types \& Manufacturing Processes. http://glassed.vitroglazings.com/glasstopics/how_lowe_works.aspx

WBDG, (2018). Whole building design guide. A program of the national institute of building science. Windows and Glazing. https://www.wbdg.org/resources/windows-and-glazing 
Window, (2018): A computer program for calculating total window thermal performance indices. THERM 7 / WINDOW 7. NFRC Simulation Manual. National Fenestration Rating.

Yin, R., Xu, P. and Shen, P. (2012). Case study: Energy savings from solar window film in two commercial buildings in Shanghai. Energy and Buildings 45 (2012) 132-140. C 2011 Elsevier B.V. All rights reserved. 